\title{
AFRIKANER IN DER MINOISCHEN IKONOGRAPHIE? ZUM FREMDENBILD IN DER BRONZEZEITLICHEN ÄGÄIS*
}

Von Fritz Blakolmer

Neufunde und Forschungsergebnisse der vergangenen Jahre haben unser Bewußtsein für Ethnika und interkulturelle Kontakte in der ostmediterranen Bronzezeit deutlich geschärft. ${ }^{1}$ Bei der Definition von Ägäern in der ägyptischen Bildkunst, ${ }^{2}$ ägäischen
Kunsthandwerkern im Vorderen Orient und in Ägypten, ${ }^{3}$ dem interregionalen Handels- und Preziosenaustausch und anderen Formen kultureller Interaktion $^{4}$ blieb m.E. jedoch ein Themenbereich weitgehend unberücksichtigt, und zwar die Frage

\footnotetext{
* Für Diskussionen bzw. die Durchsicht des Manuskriptes danke ich Stefan Hiller sowie Karl R. Krierer und für die redaktionelle Betreuung Ernst Czerny. Eine Kurzfassung der Überlegungen zum Wandbild des, Captain of the Blacks' erscheint in Kürze: F. BLAKolmer, ,Black Minos'? Zum minoischen Fresko des sog. ,Captain of the Blacks', in: B. Asamer, W. Wohlmayr (Hrsg.), Akten des 9. Österreichischen Archäologentages, 7.-9. Dezember 2001, Salzburg (im Druck).
}

1 Siehe W. V. Davies, L. Schofield (eds.), Egypt, the Aegean and the Levant. Interconnections in the Second Millennium BC (London 1995); Trade, Power and Cultural Exchange: Hyksos Egypt and the Eastern Mediterranean World 1800-1500 B.C. An International Symposium, Wednesday, November 3, 1993, ÄङL 5 (1995); E. H. Cline, D. Harris-Cline (Hrsg.), The Aegean and the Orient in the Second Millennium. Proceedings of the $50^{\text {th }}$ Anniversary Symposium Cincinnati, 18-20 April 1997, Aegaeum 18 (1998); A. CAUBET (Hrsg.), L'acrobate au taureau. Les découvertes de Tell el-Dabc a (Égypte) et l'archéologie de la Méditerranée orientale (1800-1400 av. J.-C.). Actes du colloque organisé au musée du Louvre par le Service culturel le 3

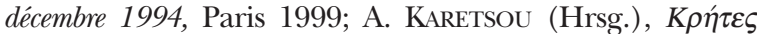

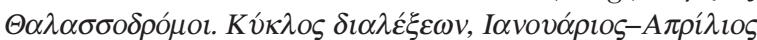
1996, Irakleio 1999; К

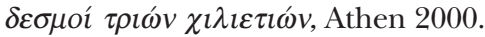

2 S. WAChSMAnN, Aegeans in the Theban Tombs, Louvain 1987; P. W. HAIDER, Ägäer in ägyptischen Diensten zwischen ca. 1550 und 1200 v.Chr., Laverna 1 (1990), 18-49; Idem, Menschenhandel zwischen dem ägyptischen Hof und der minoisch-mykenischen Welt?, $\ddot{A} \mathcal{E} L$ 6 (1996), bes. 138-142; L. SchofIELD, R. B. PARKInSON, On helmets and heretics: A possible Egyptian representation of Mycenaean warriors on a papyrus from elAmarna, BSA 89 (1994), 157-170 (gegen eine Deutung der Helmträger als Mykener: P. W. HAIDER in: B. AsAMER, W. Wohlmayr (Hrsg.), Akten des 9. Österreichischen Archäologentages, 7.-9. Dezember 2001, Salzburg [im Druck]); P. REHAK, Aegean breechcloth, kilts, and the Keftiu paintings, AJA 100 (1996), 35-51; L. PINCH BROCK, Art, industry and the Aegeans in the tomb of Amenmose, $\ddot{A} \mathcal{E} L 10$ (2000), 127-137; D. Panagiotopoulos, Keftiu in context: Theban tomb-paintings as a historical source, Oxford Journal of Archaeology 20 (2001), 263-283.
${ }^{3}$ Siehe bes. M. BiETAK, Die Wandmalereien aus Tell elDabca ('cEzbet Helmi). Erste Eindrücke, ÄEL 4 (1994), 44-58; Idem, N. MARINATOS, The Minoan wall paintings from Avaris, in: Trade, Power and Cultural Exchange: Hyksos Egypt and the Eastern Mediterranean World 1800-1500 B.C. An International Symposium, Wednesday, November 3, 1993, ÄEL 5 (1995), 49-62; L. MoRGAN, Minoan painting and Egypt. The case of Tell El-

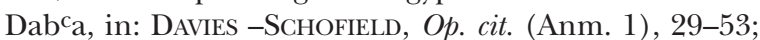
W.-D. NiEmeIER, Tel Kabri: Aegean fresco paintings in a Canaanite palace, in: S. GITIN (Hrsg.), Recent Excavations in Israel. A View to the West, Reports on Kabri, Nami, MiqneEkron, Dor, and Ashkelon, Archaeological Institute of America, Colloquia and Conference Papers 1, Dubuque 1995, 1-15; B. und W.-D. NiEmEIER, Aegean frescoes in Syro-Palestine: Alalakh and Tel Kabri, in: S. SHerratT (Hrsg.), Proceedings of the First International Symposium 'The Wall Paintings of Thera', 30 August-4 September 1997, II, Athen 2000, 763-800; Idem, Minoan frescoes in the eastern Mediterranean, in: Cline, Harris-Cline, op. cit. (Anm. 1), 69-98.

${ }^{4}$ Beispielhaft seien erwähnt P. W. HAIDER, Griechenland Nordafrika. Ihre Beziehungen zwischen 1500 und 600 v.Chr. (Darmstadt 1988); Idem, Zu den ägyptisch-ägäischen Handelsbeziehungen zwischen ca. 1370 und 1200 v.Chr., 1. Das Handelssystem, Münstersche Beiträge 7 (1988), 12-24; Idem, Zu den ägyptisch-ägäischen Handelsbeziehungen zwischen ca. 1370 und 1200 v.Chr., 2. Handelsgüter und Handelswege, Münstersche Beiträge 8 (1989), 1-26; Idem, Op. cit. (Anm. 2, 1996), 137-156; E. H. CLINE, Contact and trade or colonization?: Egypt and the Aegean in the $14^{\text {th }}-13^{\text {th }}$ centuries B.C., Minos 25/26 (1990/91), 7-36; Idem, Sailing the Wine-Dark Sea. International Trade and the Late Bronze Age Aegean, BAR-IS 591 (Oxford 1994); Idem, Tinker, tailor, soldier, sailor: Minoans and Mycenaeans abroad, in: R. LAFFineur, W.D. Niemeier (Hrsg.), POLITEIA. Society and State in the Aegean Bronze Age. Preceedings of the $5^{\text {th }}$ International Aegean Conference, University of Heidelberg, 10-13 April 1994, Aegaeum 12, I (1995), 265-283; Idem, The nature of the economic relations of Crete with Egypt and the Near East during the Late Bronze Age, in: A. Chaniotis (Hrsg.), From Minoan Farmers to Roman Traders. Sidelights on the Economy of Ancient Crete, Stuttgart 1999, 115-144; 
nach dem Bild des Fremden in der minoisch-mykenischen Ikonographie. ${ }^{5}$

$\mathrm{Da}$ Schwarzafrikaner, die hier aus Gründen der Methodik im Zentrum unseres Interesses stehen werden, in unterschiedlichen Funktionen, etwa als Händler, Seeleute, Diplomaten, Flüchtlinge, Söldner oder Sklaven, in der Ägäis physisch präsent gewesen sein könnten und dies wohl auch tatsächlich waren, ${ }^{6}$ soll nicht das Thema dieses Artikels sein. Vielmehr wird im folgenden die Frage nach der Bildwürdigkeit des Fremden in der repräsentativen Ikonographie der bronzezeitlichen Ägäis gestellt.

Mutmaßliche Darstellungen von Afrikanern sind in der frühägäischen Bildwelt prima vista nicht nur äußerst spärlich, sondern geradezu alle Beispiele stehen m.E. auf wackeligen Beinen in bezug auf eine einwandfreie Zuordnung. ${ }^{7}$ Als am meisten

J. Phillips, False analogies: The Minoan origin of some

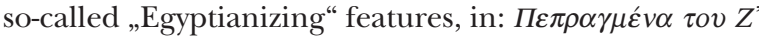

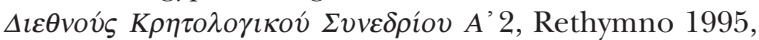
$757-765$.

5 Dazu bislang v.a. PoM II, 755-757, Taf. XIII; H.-G. BUCHHOLZ, Die Schleuder als Waffe im ägäischen Kulturkreis, in: Helmuth Theodor Bossert'in hatırastına armağan, Anadolu Arasstırmaları 2 (1965), bes. 139-143; P. W. HAIDER, Grundsätzliches und Sachliches zur historischen Auswertung des bronzezeitlichen Miniaturfrieses auf Thera, Klio 61 (1979), 285-307, bes. 291 mit Anm. 33; Idem, Die Anwesenheit von Negern in der minoischmykenischen Welt, ÖJh 55 (1984), 187; Idem, Op. cit. (Anm. 4, Darmstadt 1988), bes. 99 Anm. 82. Siehe ferner P. CARLIER, L'étranger dans le monde mycénien, in: R. LonIz (Hrsg.), L'Étranger dans le monde grec. Actes du colloque organisé par l'Institut d'Études Anciennes, Nancy, mai 1987, Travaux et mémoires de l'Université de Nancy 2, Études anciennes 4, Nancy 1988, 7-21.

6 Dazu Carlier, Op. cit. (Anm. 5), 7-21; Haider, Op. cit. (Anm. 2, 1996), 137-156. Siehe allg. G. L. Hoffman, Imports and Immigrants. Near Eastern Contacts with Iron Age Crete, Ann Arbor 1997.

7 Zur Darstellung von Afrikanern in der Bildkunst des Klassischen Altertums und zur Methodik der Interpretation siehe bes. G. H. BeARdsley, The Negro in Greek and Roman Civilization, Baltimore 1929; L. Bugner (Hrsg.), The Image of the Black in Western Art I. From the Pharaos to the Roman Empire, Cambridge, Mass.-London 1976; F. SNOWDEN, Iconographical evidence on the black populations in Greco-Roman antiquity, in: J. VERCOUTTER, J. LECLANT, F. SNOWden (Hrsg.), The Image of the Blacks in Western Art, Lausanne 1976, 133-245; Idem, Before Colour Prejudice. The Ancient View of Blacks, London 1983, bes. 46-59; S. MANSER, Schwarzafrikaner in der griechischen Kunst, unpubl. Diplomarbeit, Wien 1995. Zum Bild des ,Fremden“ im Klassischen Altertum siehe allg. K. E. MüLLER, Geschichte der antiken Ethnographie und ethnologi-
Erfolg versprechendes Bestimmungskriterium bietet sich die Dunkelhäutigkeit an, doch wird in der Forschung bis heute oft mit Argumenten physiognomischer Differenzierung operiert - beides Ansätze, die in den meisten der vorliegenden Fälle in die Irre führen können.

\section{DiSKuSSION MÖgLICHER AFRIKANERBILDNISSE IN DER MINOISCHEN KUNST}

Die dunkelgraue Färbung der nackten, breitgesäßigen ,Schwimmer" vor hellem Grund auf Fayencetafeln des sogenannten ,Stadt-Mosaiks' aus Knossos ${ }^{8}$ (Abb. 1) ist chromatisch aller Wahrscheinlichkeit nach nicht als Kennzeichnung von tatsächlich Schwarzhäutigen, sondern vielmehr unter dem Aspekt des dekorhaften, dreifarbigen Kamares-Kolorits jener Zeit zu verstehen, ${ }^{9}$ wie ja auch das sehr oft schwarze Inkarnat unwesentlich älterer, bemalter

schen Theoriebildung I, Wiesbaden 1972; W. RAECK, Zum Barbarenbild der Kunst Athens im 6. und 5. Jahrhundert v. Chr., Bonn 1981; H. SonNABEnd, Fremdenbild und Politik, Frankfurt 1986; A. DiHLE, Die Griechen und die Fremden, München 1994; M. Schuster (Hrsg.), Die Begegnung mit dem Fremden, Stuttgart-Leipzig 1996.

8 Dazu A. J. Evans, The palace of Knossos, BSA 8 (1901/ 02), bes. 20; PoM I, 309-312 Abb. 228. 230 („,... the steatopygous rump, abdominal prominence, and prognathism ... are clearly negroid"); II, 756f., Abb. 489; IV, 887 Anm. 1; W. S. SMITH, Interconnections in the Ancient Near East. A Study of the Relationship between the Arts of Egypt, the Aegean, and Western Asia, New Haven-London 1965, 67, Abb. 87a; S. Hood, The Arts in Prehistoric Greece, Harmondsworth 1978, 132; K. P. Foster, Aegean Faience of the Bronze Age, New Haven-London 1979, 100f., Abb. 30, 31;

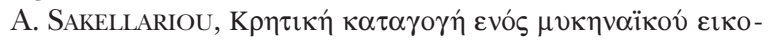

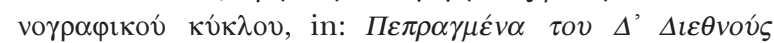

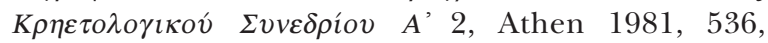
Taf. 183a; S. A. ImMERWAHr, A possible influence of Egyptian art in the creation of Minoan wall painting, in: P. DarcQue, J.-C. Poursat (Hrsg.), L'iconographie minoenne. Actes de la table ronde d'Athènes (21-22 avril 1983), BCH Suppl. XI, Paris 1985, 47; H. Waterhouse, The Knossos „Town Mosaic" reconsidered, Cretan Studies 4 (1994), 165-174, Taf. XXI-XXVI.

9 Dazu demnächst F. Blakolmer, Colour in the Aegean Bronze Age: From Monochromy to Polychromy, in: L. Cleland, G. Davies, K. Stears (Hrsg.), Colours in Antiquity: Towards an Archaeology of Seeing, Conference, University of Edinburgh, 10 th-13 th September 2001 (in Druckvorbereitung). Erwähnt sei, daß bekanntlich auch bei allen übrigen (jüngeren) Beispielen dieses ,ikonographischen Zyklus' keine Schwarzafrikaner dargestellt wurden. Siehe bes. P. WARREN, The miniature fresco from the West House at Akrotiri, Thera, and its Aegean setting, JHS 99 (1979), bes. 125-128; A. SAKELlariou, The West House miniature frescoes, in: CH. Doumas (Hrsg.), 

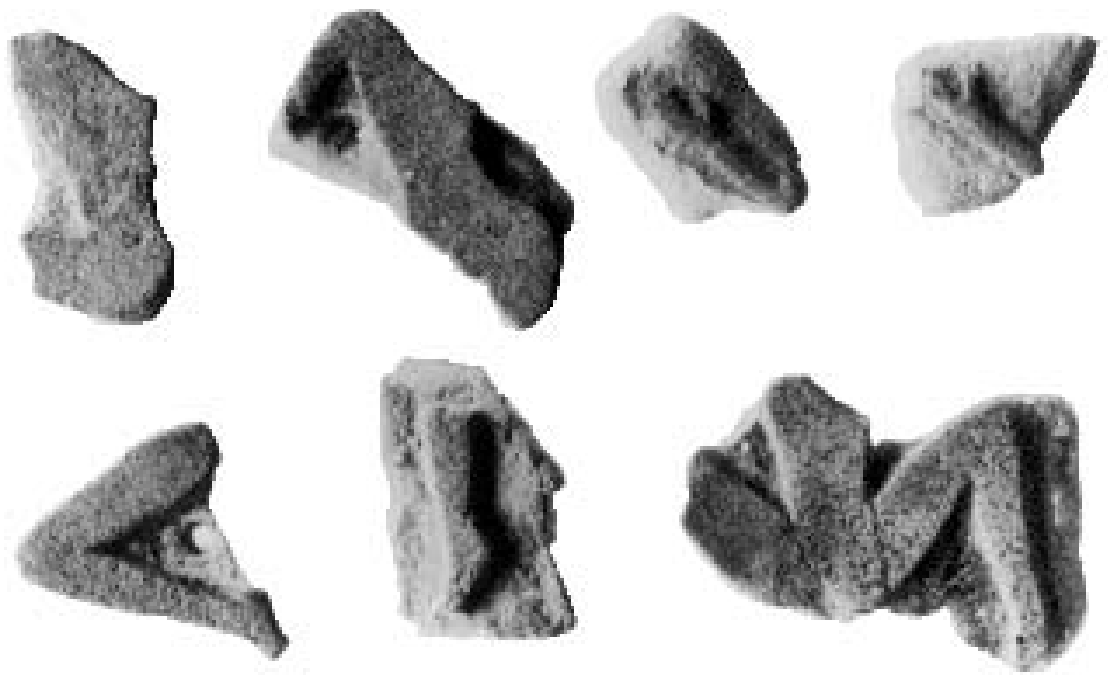

Abb. 1 Fayencetafeln des ,Stadt-Mosaiks', Knossos

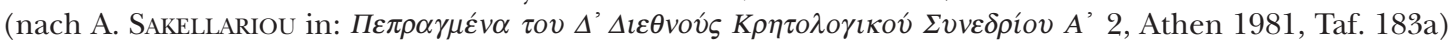

männlicher Tonstatuetten des Mittelminoikums (Abb. 2) nicht als Kenntlichmachung einer Vielzahl frommer Schwarzafrikaner in kretischen Heiligtümern verstanden werden kann. ${ }^{10}$

Der altpalastzeitliche Miniaturkopf im Muschelrelief mit Wulstlippen und Stupsnase aus Agios Onouphrios $^{11}$ (Abb. 3), heute im Ashmolean Museum in Oxford, zeigt einen vor allem durch Bohrungen angedeuteten Vollbart und besaß eine in anderem Material eingesetzte Pupille sowie eine applizierte Haarkalotte. Die Inkarnatspartien des Kopfes verblieben folglich wohl in problemlos kontrastierendem Muschelweiß und entbehrten jeg-

Thera and the Aegean World, Papers Presented at the Second International Scientific Congress, Santorini, Greece II, London 1980, 147-152; Eadem, Op. cit. (Anm. 8), 532-538.

10 Zum Körperkolorit männlicher Tonfigurinen des Mittelminoikums in Schwarz oder Rot siehe bes. B. Rutkowski, Petsophas. A Cretan Peak Sanctuary, Warschau 1991, 22 mit Anm. 3; S. 31; N. Platon, To ıєрóv

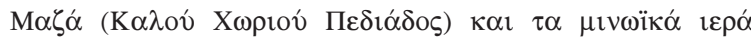
корטчท́, Kretika Chronika 5 (1951), 107; R. A. HigGINS, Greek Terracottas, London 1967, 9; E. N. DAvIS, The Egyptian influence on Minoan figure painting, in:

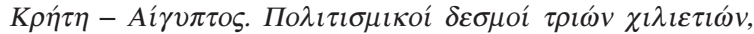
Athen 2000, bes. 64f.

11 Zu diesem Stück bes. PoM II, 45f., Abb. 21 a-b; J. Shackleton, S. Hood, J. Musgrave, The Ashmolean shell plaque (AM 1938.537), BSA 82 (1987), 284-295, Taf. 43-45. Siehe weiters etwa Hood, Op. cit. (Anm. 8), 116, Abb. 102.

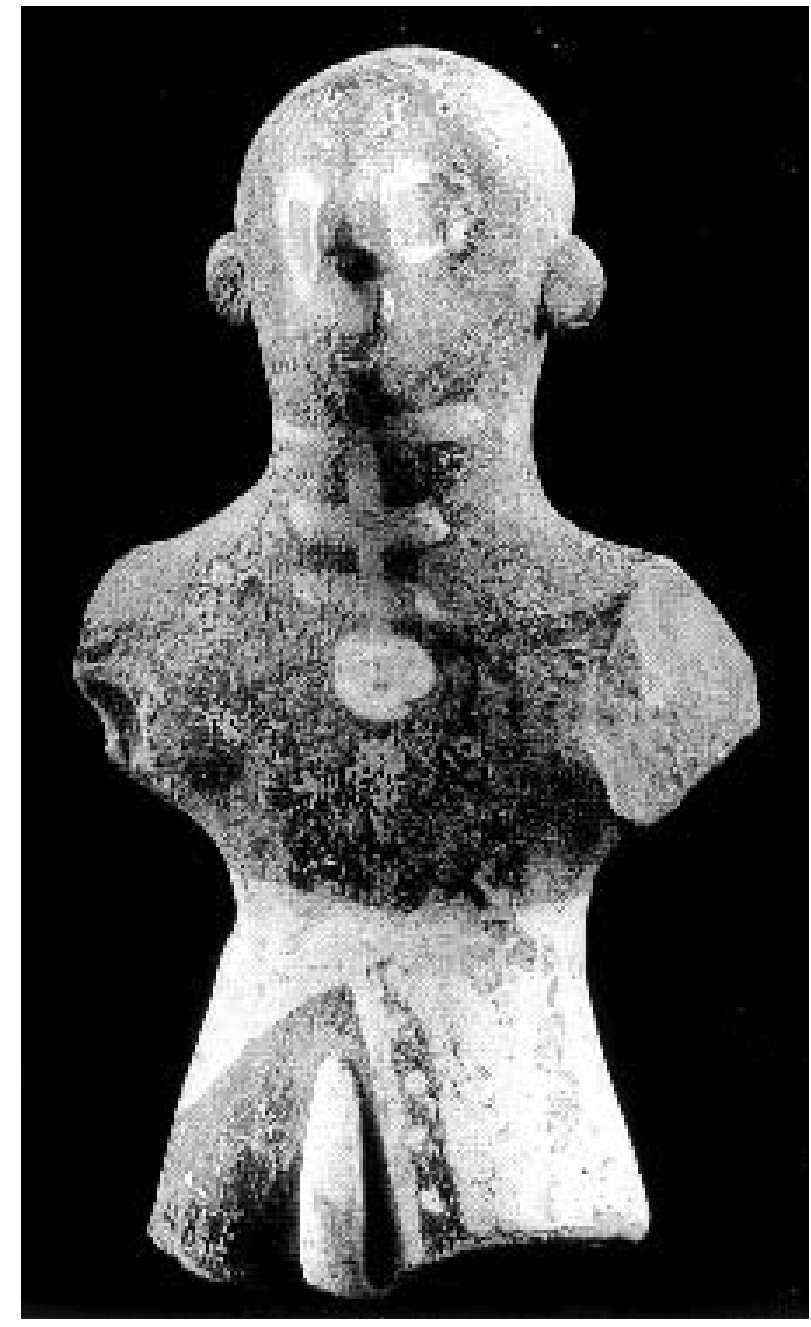

Abb. 2 Mittelminoische Tonfigurine vom Petsophas,

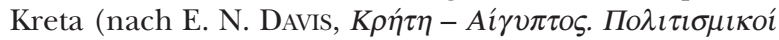

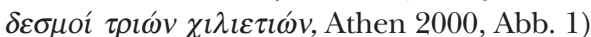




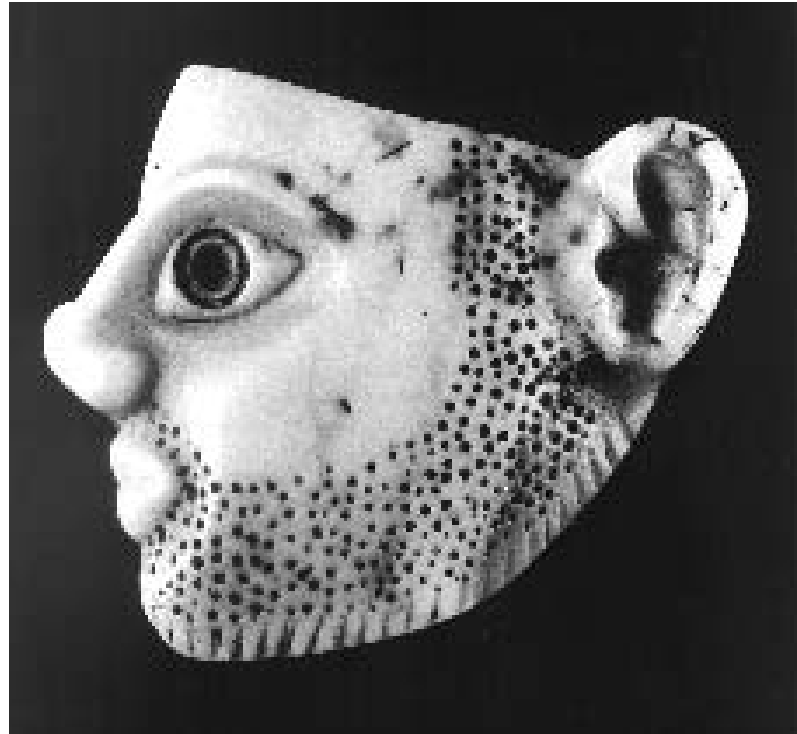

Abb. 3 Muschelrelief aus Agios Onouphrios, Kreta (nach F. SNOwden in: J. Vercoutter u.a. [Hrsg.], The Image of the Blacks in Western Art, Lausanne 1976, 134, Abb. 142)

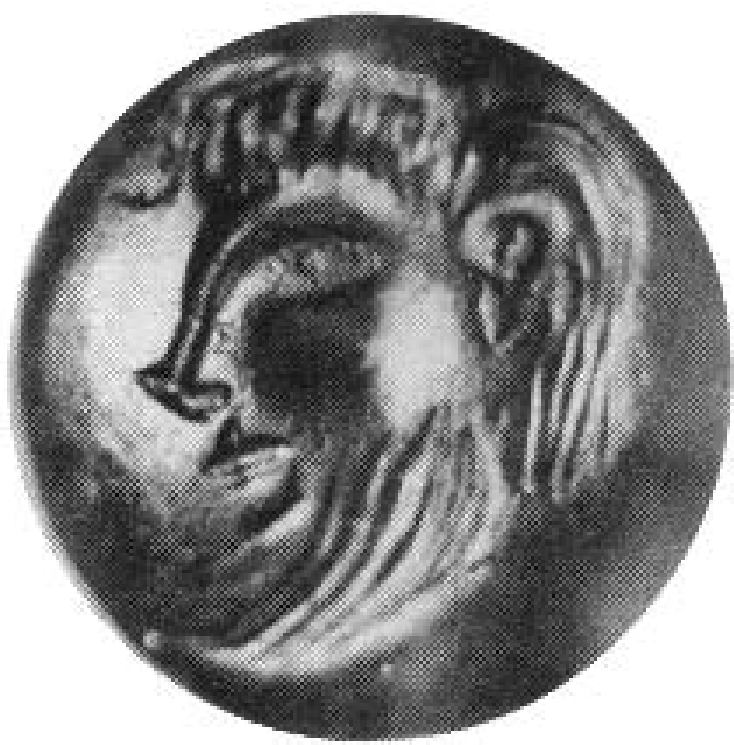

Abb. 4 Siegel aus ,Schachtgräberrund B' in Mykene

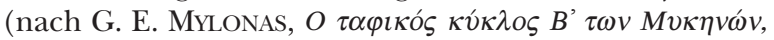
Athen 1973, Farbtafel 10)

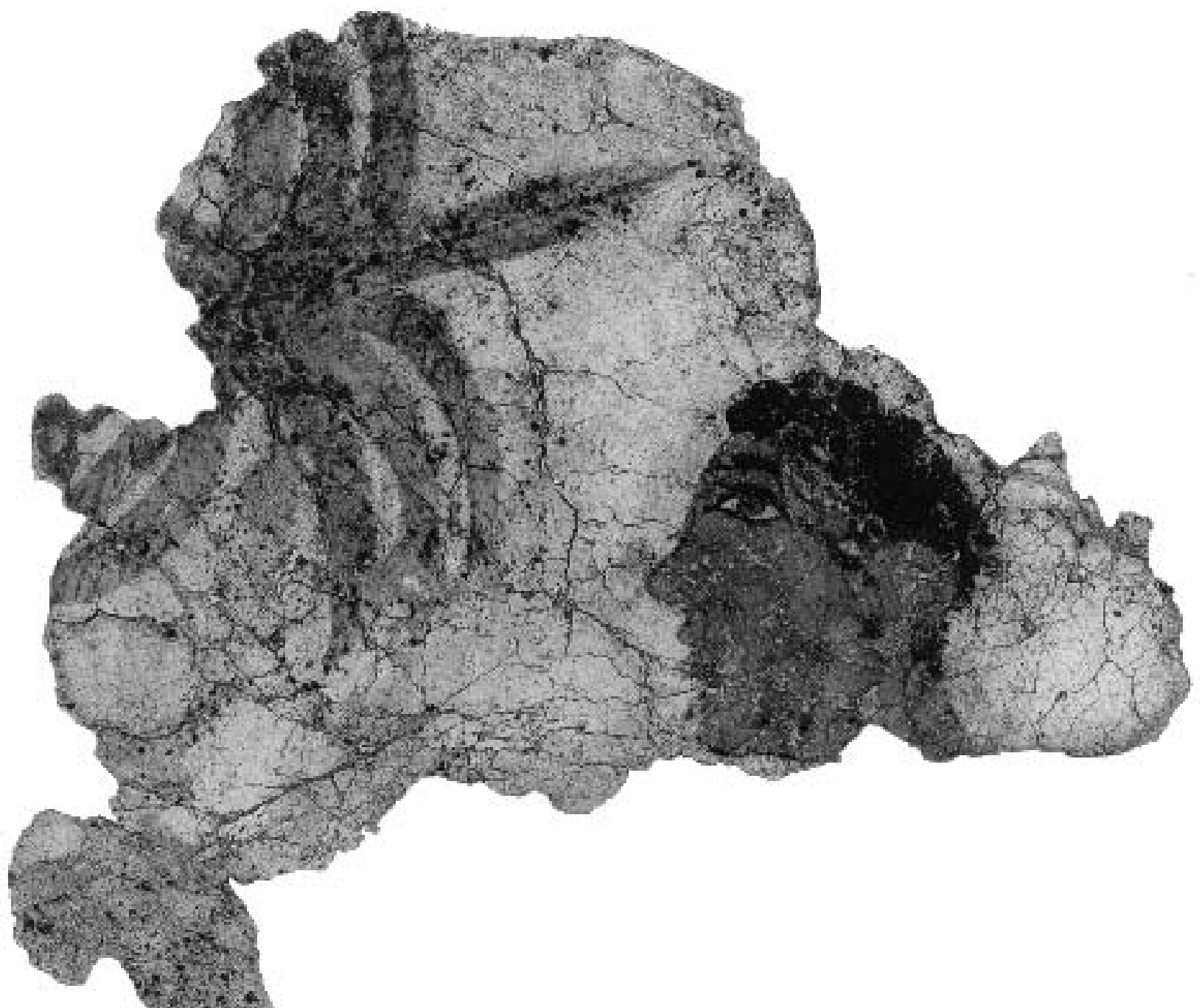

Abb. 5 Wandmalereifragment aus Akrotiri, Thera

(nach CH. Doumas, The Wall-paintings of Thera, Athen 1992, 187, Abb. 148) 
licher Bemalung. Wulstige Nase, großes Auge, verdickte Lippen und seltsamerweise auch der Vollbart des Köpfchens werden dennoch in der Forschung generell als Charakteristika eines Schwarzafrikaners angesehen - und dies ungeachtet der unbemalten hellen Hautpartien. Nur oberflächlich erinnert der gepunktete Bart an die Wiedergabe der krausen Buckellocken des Haupthaares in Äthiopierdarstellungen des Klassischen Altertums ${ }^{12}$ - ein unzutreffender Vergleich, der uns den Blick bei der Beurteilung verstellen könnte. Die genannten physiognomischen Züge dieses Menschenbildes begegnen jedenfalls häufig auch an Frühägäern, ${ }^{13}$ wie beispielsweise ein prominentes Amethyst-Siegel aus

${ }^{12}$ Vgl. etwa die Busiris-Darstellung auf einem rotfigurigen Stamnos aus Vulci, heute in Oxford, wiedergegeben bei SNOWDEn, Op. cit. (Anm. 7, 1976), 152, Abb. 168. Siehe weiters oben (Anm. 7).

13 So zuletzt auch S. Hood in: SHAckleton, Hood, MusGRAVE, Op. cit. (Anm. 11), 289-293. Skeptisch gegenüber der Ansprache als Nicht-Ägäer äußerten sich bereits B. KAISER, Untersuchungen zum minoischen Relief, Bonn 1976, 229 (hier der Jüngeren Palastzeit zugewiesen); I. PINI, Minoische ,Porträts'?, in: PH. P. Betancourt, V. Karageorghis, R. Laffineur, W.-D. NiEMEIER (Hrsg.), MELETEMATA. Studies in Aegean Archaeology Presented to Malcolm H. Wiener as he enters his $65^{\text {th }}$ Year, Aegaeum 20, III, (1999), 665.

14 Zu diesem Siegel aus Schachtgrab $\Gamma$ siehe CMS I Nr. 5;

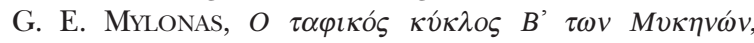
Athen 1973, 77f., Taf. 60 und Farbtaf.; H. BiesantZ, Die minoischen Bildnisgemmen, MarbWPr 1958, 10 (Nr. 4), Taf. 10; C. W. Blegen, Early Greek portraits, AJA 66 (1962), 247, Taf. 61.7; J. H. BETTs, The seal from Grave Gamma: A ,Mycenaean Chieftain'?, in: Temple University Aegean Symposium 6, Philadelphia 1981, 2-8; I. PINI, Minoische Siegel ausserhalb Kretas, in: R. HäGG, N. Marinatos (Hrsg.), The Minoan Thalassocracy. Myth and Reality, Proceedings of the Third International Symposium at the Swedish Institute in Athens, Stockholm 1984, bes. 128f. zu Abb. 8; Idem, Op. cit. (Anm. 13), bes. 665; H. Wingerath, Studien zur Darstellung des Menschen in der minoischen Kunst der älteren und jüngeren Palastzeit, Marburg 1995, 89f. Als „östlicher Abstammung verdächtig“" bewertete BuchHolz, Op. cit. (Anm. 5), 141, jedoch auch diesen Kopf.

15 Zur Deutung als Schwarzafrikaner siehe bes. S. MARINATOS, Excavations at Thera II, Athen 1969, 54, Taf. B.3 und 4; Idem, An African in Thera?, AAA 2 (1969), 374f.; Idem, Ethnic problems raised by recent discoveries on Thera, in: R. A. Crossland, A. Birchall (Hrsg.), Bronze Age Migrations in the Aegean: Archaeological and Linguistic Problems in Greek Prehistory. Proceedings of the First International Colloquium on Aegean Prehistory, Sheffield, London 1973, 199-201 mit Farbtaf. 1 („kind of bedouin“); E.
Schachtgräberrund B in Mykene (Abb. 4) veranschaulicht, ${ }^{14}$ das uns, obgleich in einer jüngeren minoischen Bildtradition als das Köpfchen aus Agios Onouphrios stehend, durchaus vergleichbare Charakteristika der altkretischen Gesichtsschilderung vor Augen führt.

Bei der größerformatigen Figur mit rotbraunem Inkarnat vor einer Palme im sog. ,Afrikaner-Fresko“ aus dem theräischen Akrotiri ${ }^{15}$ (Abb. 5) wiederum handelt es sich nach heutigem Wissen bekanntlich ebensowenig um einen Afrikaner, ${ }^{16}$ wie wir es bei Spyridon Marinatos' "Libyern " ${ }^{\text {"17 }}$ in den Wandbildern des ,West-Hauses' an diesem Fundplatz mit Nordafrikanern zu tun haben. ${ }^{18}$ Frisur, Physiognomie,

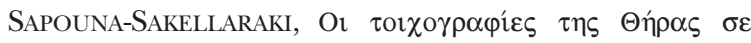

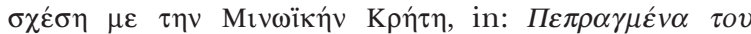

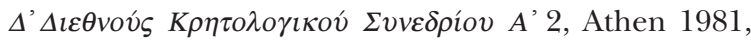
$502 \mathrm{f}$.

${ }^{16}$ Siehe bes. die klärende Diskussion bei HAIDER, Op. cit. (Anm. 5, 1979), bes. 293f.; Idem, Op. cit. (Anm. 4, Darmstadt 1988), 102f.; J. VANSCHOONWInKeL, Les fresques à figuration humaine de Théra. Analyse iconographique, Revue des Archéologues et Historiens d'Art de Louvain 16 (1983), bes. 11; N. MARINATOS, The „African“ of Thera reconsidered, OpAth 17 (1988), 137-141; L. MoRGAN, The Miniature Wall Paintings of Thera. A Study in Aegean Culture and Iconography, Cambridge 1988, $90 \mathrm{f}$.

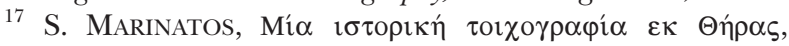
PraktAkAth 48 (1973), 231-237; Idem, Op. cit. (Anm. 15, 1973), 199-201; Idem, The „Libya Fresco“ from Thera, AAA 7 (1974), 87-94. So etwa auch D. PAGE, The miniature frescoes from Acrotiri, Thera, PraktAkAth 51 (1976), bes. 143; S. STUCCHI, Il Giardino delle Esperidi e le tappe della conoscenza greca della costa cirenaica, Quaderni di Archeologia della Libia 8 (1976), 19-73; G. KEHNSCHERPER, Frühgeschichtliche Kulturbeziehungen zwischen Kreta, Thera und Libyen, Ethnographischarchäologische Zeitschrift 21 (1980), 616-633; SAPOUNASaKellaraki, Op. cit. (Anm. 15), bes. 489-492; A. B. KnAPP, The Thera frescoes and the question of Aegean contact with Libya during the Late Bronze Age, Journal of Mediterranean Anthropology and Archaeology 1, H. 2 (1981), 249-279; A. NiBBI, Some „Libyans“ in the Thera frescoes?, Discussion in Egyptology 31 (1995), 81-98.

${ }_{18}$ Gegen diese Interpretation wandten sich bes. M. BENZI, Gli affreschi dell'ammiraglio a Thera, Prospettiva 10 (1977), 3-14; HAIDER, Op. cit. (Anm. 5, 1979), 285-307; Idem, Op. cit. (Anm. 4, Darmstadt 1988), 86-117; WARREN, Op. cit. (Anm. 9), 115-129; H. DöHL, Mykenische Kampfdarstellungen. Bild und Deutung im prähistorischen Griechenland, in: Th. KRÜGer, H.-G. StePhaN (Hrsg.), Beiträge zur Archäologie Nordwestdeutschlands und Mitteleuropas. Festschrift Klaus Raddatz, Materialhefte zur Ur- und Frühgeschichte Niedersachsens, Hildesheim 1980, 25; Morgan, Op. cit. (Anm. 16), bes. 88-92. 116-120. 


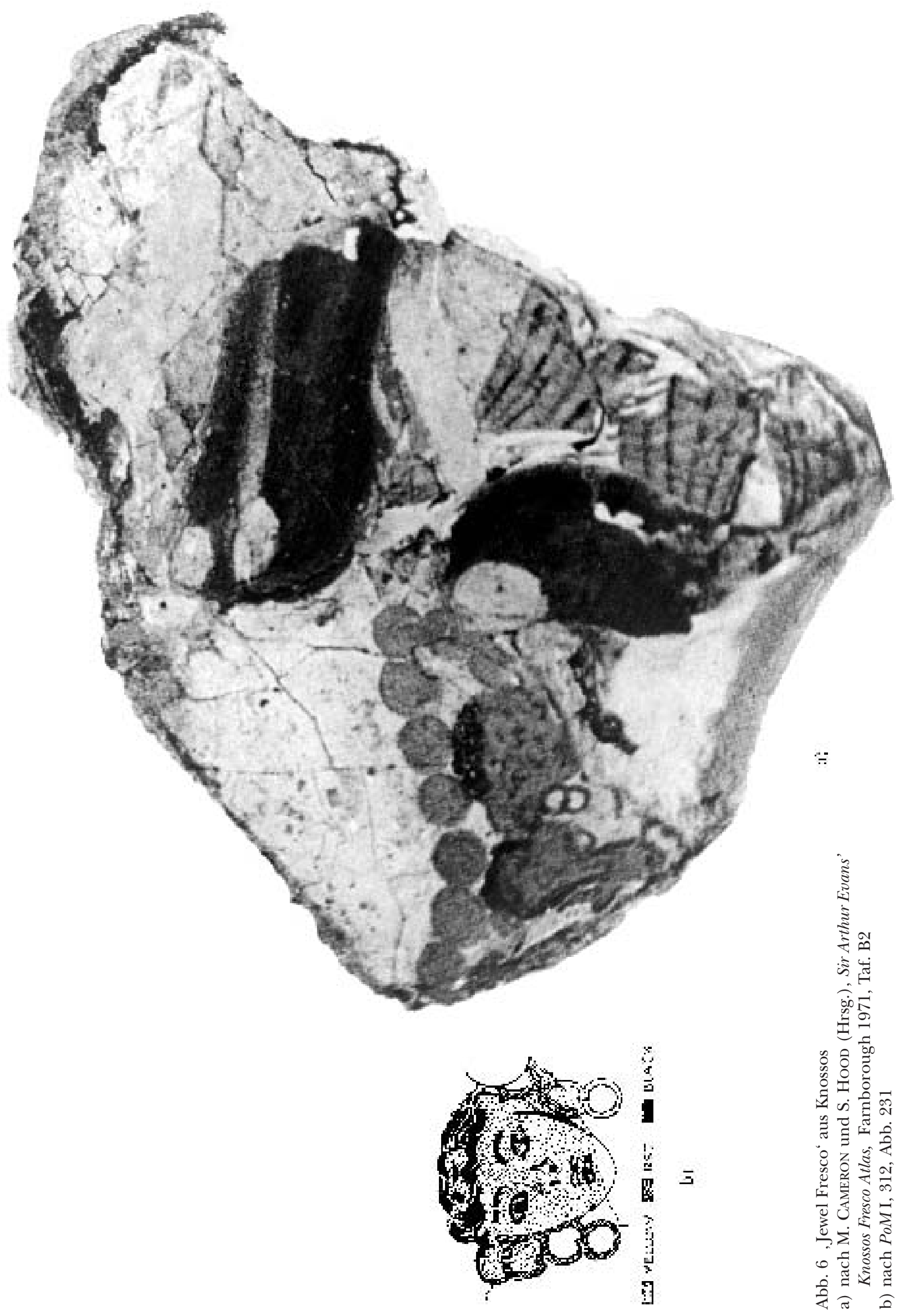


Nacktheit (von Kindern wie auch Ertrinkenden ${ }^{19}$ ) und nicht zuletzt der rotbraune Gesichtsteint haben sich bislang unzweifelhaft als Kennzeichen ägäischer Ethnizität erwiesen. ${ }^{20}$

Auf dem Stuckrelieffragment des sog. ,Jewel Fresco a aus Knossos (Abb. 6 a) dienen als Anhänger der namengebenden goldenen Halskette en face wiedergegebene Köpfe (Abb. 6 b), deren Physiognomie und vor allem Ohrringe nach Ansicht von Arthur Evans und anderen einem negroiden Menschentypus zugehörig seien. ${ }^{21} \mathrm{Da}$ Schmuck in der Bronzezeit auch von Ägäern männlichen Geschlechts getragen wurde, ist durch ikonographische Beispiele ${ }^{22}-$ Abb. 7 etwa zeigt einen Bärtigen mit Ohrring in einem Siegelbild $^{23}$ - wie auch durch archäologische Befunde in sepulkralem Kontext ${ }^{24}$ mittlerweile hinlänglich bezeugt. ${ }^{25}$ Von großen, abstehenden Ohren als ethnischem Kennzeichen ${ }^{26}$ braucht hier keineswegs die Rede sein, könnte dies doch vielmehr der ungewöhnlichen Frontalität im Schmuckhandwerk Rechnung tragen ${ }^{27}$ und besitzt das linke Ohr doch sehr wohl eine für Ägäerdarstellungen konventionelle Größe.
19 Dazu bes. Ch. Doumas, Conventions artistiques à Théra et dans la Méditerranée orientale à l'époque préhistorique, in: P. DARCQUe, J.-C. Poursat (Hrsg.), L'iconographie minoenne. Actes de la table ronde d'Athènes (21-22 auril 1983), BCH Suppl. XI, Paris 1985, bes. 33; Idem, Trade in the Aegean in the light of the Thera excavations, in: M. Marazzi, S. Tusa, L. Vagnetti (Hrsg.), Traffici micenei nel Mediterraneo. Problemi storici e documentazione archeologica. Atti del convegno di Palermo (11-12 maggio e 3-6 dicembre 1984), Taranto 1986, bes. 235.

20 Zum Inkarnatskolorit in der frühägäischen Ikonographie siehe etwa S. Damiani Indelicato, Were Cretan girls playing at bull-leaping?, Cretan Studies 1 (1988), 39-47; N. MARINATOS, Role and sex division in ritual scenes of Aegean art, JPR 1 (1987), 23-34; F. BLAKOLMER, Überlegungen zur Inkarnatsfarbe in der frühägäischen Malerei, Ö/h 62 (1993), Hauptbl., 5-18; M. A. EAVERLY, Color and gender in ancient painting: a panMediterranean approach, in: N. L. WICKER, B. ARNOLD (Hrsg.), From the Ground Up: Beyond Gender Theory in Archaeology. Proceedings of the Fifth Gender and Archaeology Conference, University of Wisconsin, Milwaukee, October 1998, BAR-IS 812, Oxford 1999, 5-10.

21 PoM I, 312 Abb. 231; S. 525f., Abb. 383; K. MÜLLER, Frühmykenische Reliefs aus Kreta und vom griechischen Festland, JdI 30 (1915), 272; M. A. S. Cameron, The ,palatial' thematic system in the Knossos murals. Last notes on Knossos frescoes, in: R. HäGG, N. MarInATOS (Hrsg.), The Function of the Minoan Palaces. Proceedings of the Fourth International Symposium at the Swedish Institute in Athens (Stockholm 1987) 322-324 Abb. 1, 5; M. EFFINGER, Minoischer Schmuck (Oxford 1996) 68f., Taf. 66a; K. P. Foster, Visage and likeness in Minoan Art, in: R. LAFFineur, PH. P. Betancourt (Hrsg.), TEXNH. Craftsmen, Craftswomen and Craftsmanship in the Aegean Bronze Age. Proceedings of the $6^{\text {th }}$ International Aegean Conference, Philadelphia, Temple University, 18-21 April 1996, Aegaeum 16, I (1997), 136; D. Evely (Red.), Fresco: A Passport into the Past. Minoan Crete through the Eyes of Mark Cameron, Athen 1999, 164 mit Abb.

22 Dazu bes. E. Bielefeld, Schmuck, ArchHom C, Göttingen 1968, 36f.; W.-D. NiemeIER, Das Stuckrelief des „Prinzen mit der Federkrone“ aus Knossos und minoische Götterdarstellungen, AM 102 (1987), bes. 89; HAIDER, Op. cit. (Anm. 5, 1979), 293; Idem, Op. cit. (Anm.
4, Darmstadt 1988), 100, 102; Marinatos, Op. cit. (Anm. 16), bes. 137f.; O. SARGNON, Les bijoux préhelléniques, Paris 1987, 59-63; J. G. Younger, Representations of MinoanMycenaean jewelry, in: R. LAffineur, J. L. Crowley (Hrsg.), EIK $\Omega N$. Aegean Bronze Age Iconography: Shaping a Methodology. Proceedings of the $4^{\text {th }}$ International Aegean Conference, University of Tasmania, Hobart, Australia, 6-9 April 1992, Aegaeum 8 (1992), bes. 260f.; EFfinger, Op. cit. (Anm. 21), bes. 59 .

23 CMS VIII Nr. 110 b; PINI, Op. cit. (Anm. 13), 668, Taf. CXLI:h. Vgl. auch die Darstellung auf einem Siegel in Zürich: CMS X Nr. 278.

24 Dazu E. M. Konstantinidi, Jewellery Revealed in the Burial Contexts of the Greek Bronze Age, BAR-IS 912, Oxford 2001, bes. 247f.; I. Kilian-Dirlmeier, Noch einmal zu den »Kriegergräbern« von Knossos, JbRGZM 32 (1985), bes. 205-207; Eadem, Beobachtungen zu den Schachtgräbern von Mykenai und zu den Schmuckbeigaben mykenischer Männergräber, JbRGZM 33, H.1 (1986), 159-198 (ebenda 187, Tabelle 7 allerdings negative Evidenz für Ohrringe bei Männerbestattungen vermerkt). Zum ägäischen Charakter ineinander gehängter Ohrringe vgl. EFFInGER, Op. cit. (Anm. 21), 59, 76, 117 (Anm. 979).

25 Vgl. etwa auch die männliche Figur mit frontalem Kopf mit Ohrringen aus dem ,Schatz von Ägina': A. J. EvANs, A Mykênæan treasure from Aegina, JHS 13 (1892/93), 197-203 Abb. 2 a-b; R. Higgins, The Aegina treasure reconsidered, BSA 52 (1957), 45f., Taf. 9a; C. HopkIns, The Aegina treasure, AJA 66 (1962), bes. 183, Taf. 52.3; CH. GATES, Iconography at the crossroads. The Aigina treasure, in: R. LAffineur (Hrsg.), Transition. Le monde égéen du bronze Moyen au bronze Récent. Actes de la deuxième Rencontre égéenne internationale de l'Université de Liège (18-20 avril 1988), Aegaeum 3, (1989), 218-221, Taf. XLIX; Hood, Op. cit. (Anm. 8), 195, Abb. 192. Siehe weiters SArgnon, Op. cit. (Anm. 22), 86, 179 (N. 704), Abb. 170.

${ }^{26}$ So Foster, Op. cit. (Anm. 8), 100: „large tripple earrings“; Effinger, Op. cit. (Anm. 21) 28f.: „an den großen Ohren je ein Ohrring, bestehend aus mindestens drei ineinander gehängten Reifen “.

27 Es ist weiters überlegenswert, ob wir in dieser Scheibe nicht das dekorativ in die Fläche geklappte rechte $\mathrm{Ohr}$, sondern ein eigenes Kettenglied in Form einer Goldperle erkennen sollten. 


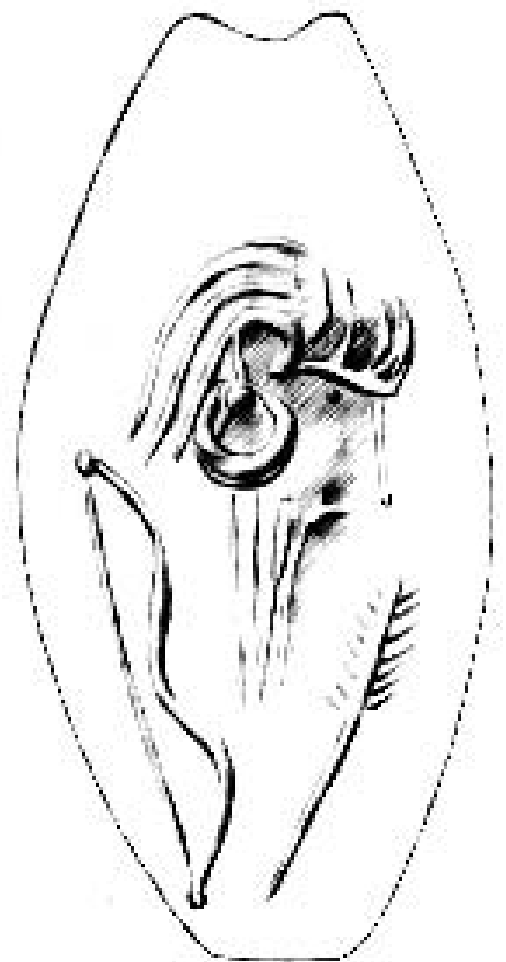

Abb. 7 Siegel in der Sammlung Hon. Robert Erskine, Seite B (nach CMS VIII Nr. 110b)

Bei ihrer Erörterung einer männlichen Bronzestatuette in Berlin (Abb. 8) mit Wulstlippen, runder Nase, betonten Augen und gegliedertem Haar mit Haarbüschel am Oberkopf griff Efi Sapouna-Sakellaraki unlängst einen Gedanken von Winifred $\mathrm{Lamb}^{28}$ auf und sprach von einem naturgetreuen Typ eines Schwarzafrikaners. ${ }^{29}$ Die markante Körperform dieser Figurine entspricht durchaus einer spätminoischen Variante, ${ }^{30}$ und Frisur sowie Schurz können problemlos als minoisch gelten; nicht hingegen das akzentuierte Gesicht, zumindest nicht auf den ersten Blick. Bei einer Klassifizierung als Individualporträt oder auch als Phänotypus eines Schwarzafrikaners müßte die Grundfrage lauten: sollten in einer kleinformatigen Gattung wie der Bronzeplastik tatsächlich übertriebene Züge eines

28 W. LAMB, Greek and Roman Bronzes (London 1929) $24 \mathrm{f}$. (Nr. 12) mit Taf. 9c: „It may be that the artist was trying to portray what were to him the eccentricities of a foreigner".

29 E. Sapouna-Sakellarakis, Die bronzenen Menschenfiguren auf Kreta und in der Ägäis, Prähistorische Bronzefunde I, 5, Stuttgart 1995, 81f., Kat.-Nr. 140, Taf. 29. Zu dieser Statuette siehe weiters U. Naumann, Subminoische und protogeometrische Bronzeplastik auf Kreta, AM Beih. 6, Berlin 1976, 28f. (S 24), Taf. 11; C. VerLinden, Les statuettes anthropomorphes crétoises en bronze et en plomb du IIIe millé-

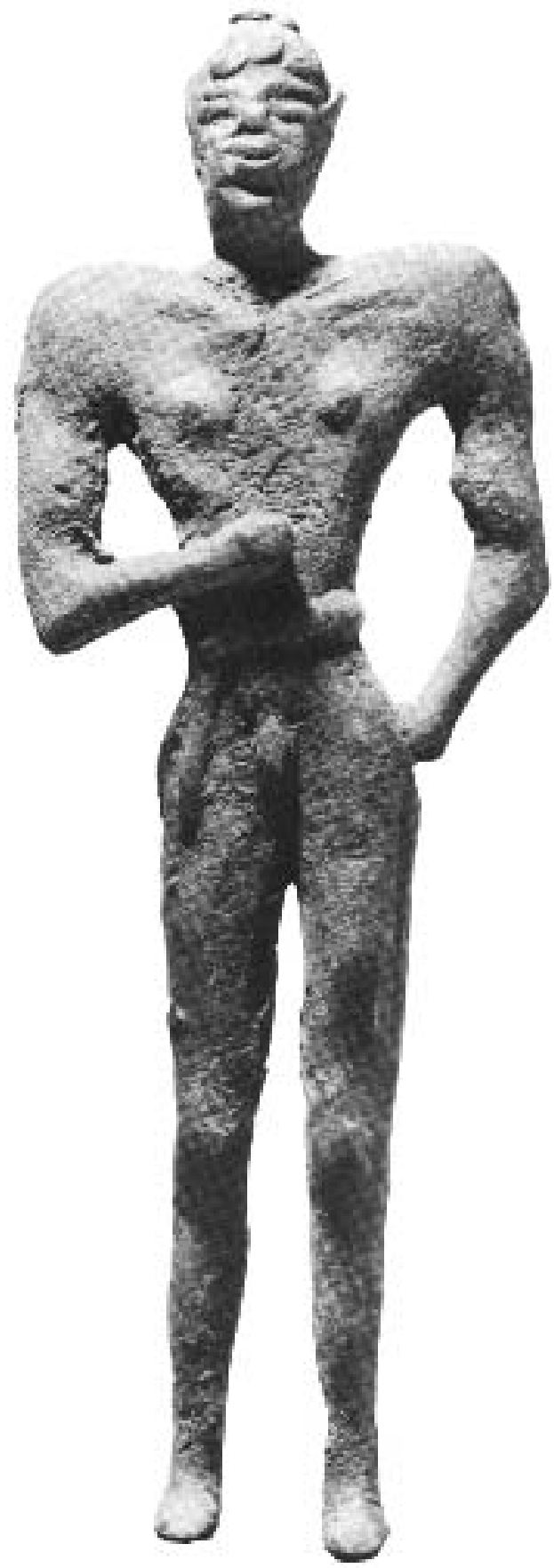

Abb. 8 Bronzestatuette in Berlin

(nach U. Naumann, Subminoische und protogeometrische Bronzeplastik auf Kreta, AM Beih. 6, Berlin 1976, Taf. 11 links)

naire au VII siècle av. J.-C., Archaeologia Transatlantica 4, Louvain-la-Neuve 1984, Nr. 11, Taf. 2; Im Labyrinth des Minos. Kreta - die erste europäische Hochkultur, Katalog zur Ausstellung des Badischen Landesmuseums, München 2000, 242f. mit Abb. (Kat. Nr. 7).

30 Und dies trotz der anthropologischen Beschreibung Negroider in der Encyclopedia Britannica als „... with triangular torso, broad shoulders and narrow waist". Dazu F. M. SNOWDEN, AJA 94 (1990), 161. 
Angehörigen einer fremden Ethnie mit traditionell ägäischer Frisur und Tracht intendiert gewesen sein, d.h. ein Afrikaner in konventionell minoischem Habitus? Auch wenn dies selbstverständlich nicht ausgeschlossen werden kann, so veranschaulichen uns Beispiele der spätminoischen Bronzeplastik, wie eine Statuette in Wien, ${ }^{31}$ daß in dieser künstlerischen Spätzeit eine unkonkrete, plumpe und beliebige Gesichtsgestaltung vorherrschte, sprach doch auch Ute Naumann von einer ,gewissen Härte in der Behandlung der Details und in deren Betonung im Rahmen des Ganzen "als Kennzeichen der späten minoischen Bronzeplastik. ${ }^{32}$

\section{2. ÜBERLEGUNGEN ZUR METHODIK}

Halten wir fest, daß keines der genannten Beispiele mit auch nur einiger Wahrscheinlichkeit als Darstellung eines Afrikaners angesprochen werden kann. Eine solche Deutung dieser und weiterer, großteils zu Beginn des 20. Jahrhunderts erstmals gedeuteter Beispiele hält beim heutigen Kenntnisstand der minoischen Bildkunst m.E. weder einer Überprüfung stand, noch läßt sie sich seither durch aussagekräftigere Neufunde stützen. Eine minoische Kenntlichmachung von Angehörigen fremder Ethnien würde eine - auch für uns - mehr oder weniger klare ikonographische Konventionalisierung, etwa in Form einer spürbaren karikierenden Überzeichnung und versehen mit charakterisierenden Attributen, voraussetzen. Ohne erkennbare, sich wiederholende ikonographische Figurentypen, die das Erstellen eines Repertoires eindeutiger Kennzeichen unterschiedlicher ,Fremdvölker' zuließen, ${ }^{33}$ besitzen wir nach wie vor nur wenige, improvisiert gestaltete Figuren, Köpfe und Gesichter, deren Deutung als ,ethnische Außenseiter" m.E. nur eine Notlösung darstellen kann. Die in der Forschung bis-

31 K. A. Neugebautr, Antike Bronzestatuetten, Berlin 1921, 24 Abb. 11; Naumann, Op. cit. (Anm. 29), 16f., Anm. 12 Taf. 1, 2; Verlinden, Op. cit. (Anm. 29), Nr. 111, Taf. 5; K. GsChwantler, Guß und Form. Bronzen aus der Antikensammlung, Wien 1986, 63 (Nr. 53) Abb. 115; R. THOMAS, Griechische Bronzestatuetten, Darmstadt 1992, 46f., Abb. 31, 32; Sapouna-Sakellarakis, Op. cit. (Anm. 29), 54 (Nr. 94, mit weiterer Literatur), Taf. 30. Die stilistische Nähe zwischen diesem Stück und der genannten Statuette in Berlin betonte bereits NaumanN, Op. cit. (Anm. 29), $16 \mathrm{f}$.

32 Naumann, Op. cit. (Anm. 29), 29.

33 Vgl. dazu die Literaturhinweise in Anm. 7.

34 A. J. Evans, The palace of Knossos, BSA 7 (1900/01), 44, Abb. 13; PoM I, 314; III, 100, 106, Abb. 59; IV, 219 Anm. 1; MÜller, Op. cit. (Anm. 21), 262f., Abb. 10; H.-G. BuCH- lang als Afrikaner angesprochenen Figuren bilden hingegen - und gerade dies erscheint bemerkenswert - durchwegs isolierte Beispiele, jeweils charakterisiert durch unkonkrete, vom geläufigen Bild des Minoers nur geringfügig abweichende Einzelmerkmale. Allein schon dieser Umstand könnte darauf hinweisen, daß eine ,Ikonographie des Fremden“ in der Bildsprache des minoischen Kreta gar nicht ausgebildet war.

Ob man beispielsweise den angreifenden Bogenschützen vor einem geschuppten Meereshintergrund auf dem Fragment eines reliefierten Serpentingefäßes aus dem neopalatialen Knossos (Abb. 9) nun als Kreter oder allgemein als Ägäer deuten möchte ${ }^{34}{ }^{34}$ weder sein Spitzbart ${ }^{35}$ noch seine

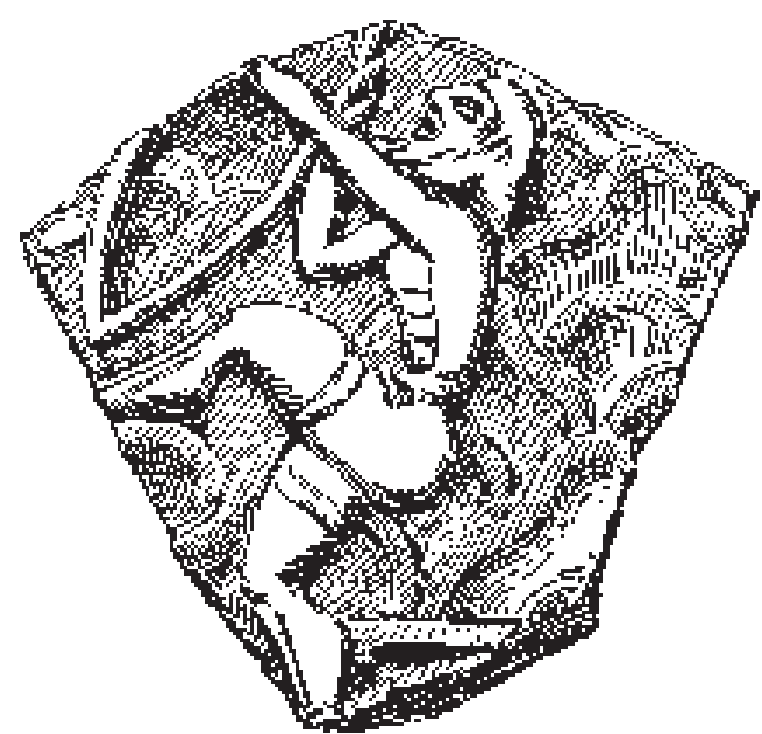

Abb. 9 Fragment eines Steinreliefgefäßes aus Knossos (nach PoM III, 106, Abb. 59)

HOLZ, Der Pfeilglätter aus dem VI. Schachtgrab von Mykene und die helladischen Pfeilspitzen, JdI 77 (1962), 2; P. WARren, Minoan Stone Vases, Cambridge 1969, bes. 177 („There is no reason to suppose that he is un-Minoan. "); SMITH, Op. cit. (Anm. 8), 71, Abb. 87b; KAISER, Op. cit. (Anm. 13), 12f. (Knossos 3), 158, 409, Anm. 539, Abb. 3. Zu einer möglichen Datierung bereits in SM IB ebenda, 181.

35 Bereits J. Boardman, The de Jong gems, in: Antichità Cretesi. Studi in onore di Doro Levi, Cronache di Archeologia 12/13, I, Catania 1973/74, 117, betonte die Ähnlichkeit des Bartes mit jenem auf manchen sog. ,Porträtgemmen'. Zum Bart in der Altägäis siehe bes. S. MARINATOS, Haar- und Barttracht, ArchHom I B, Göttingen 1967, 24-26. Evans (PoM III, 100) sprach noch von „a helmet with cheek-pieces". 
Waffe ${ }^{36}$ geschweige denn sein frühägäischer Schurz erlauben es, darin mit E. Vermeule „a sophisticated caricature of a non-Cretan, possibly a Mycenaean or Syrian, with flying beard and huge crooked nose" zu erkennen. ${ }^{37}$ Gesichtsbildung, Mimik, Gestik und physiognomische Details erscheinen auch an diesem Beispiel in keiner Weise für frühägäische Gestaltung ungewöhnlich oder in überzeichneter Sonderform, und die Realien weisen die Figur problemlos als Ägäer aus. Vergleicht man wiederum die Stadtverteidiger, Angreifer und Ertrinkenden auf dem sog. ,Belagerungsrhyton“ aus Schachtgrab IV in Myke- ne $^{38}$ (Abb. 10), das ungeachtet seines Fundortes wohl ein Thema der kretischen Ikonographie in minoischem Stil präsentiert, so vermissen wir selbst hier ein prononcierteres ethnisches ,Feind-Bild", obgleich dieses Bildwerk in der Forschung Anlaß dazu gab, zwischen bis zu drei unterschiedlichen Völkerschaften aus allen Regionen des ostmediterranen Raumes zu differenzieren: ${ }^{39}$ keine ,primitiven' oder exotischen Gewänder und Waffen, keinerlei Merkmale kultureller Fremdheit und keine physiognomisch abweichenden Gesichter kennzeichnen ein Anders-Sein vermuteter unterschied-

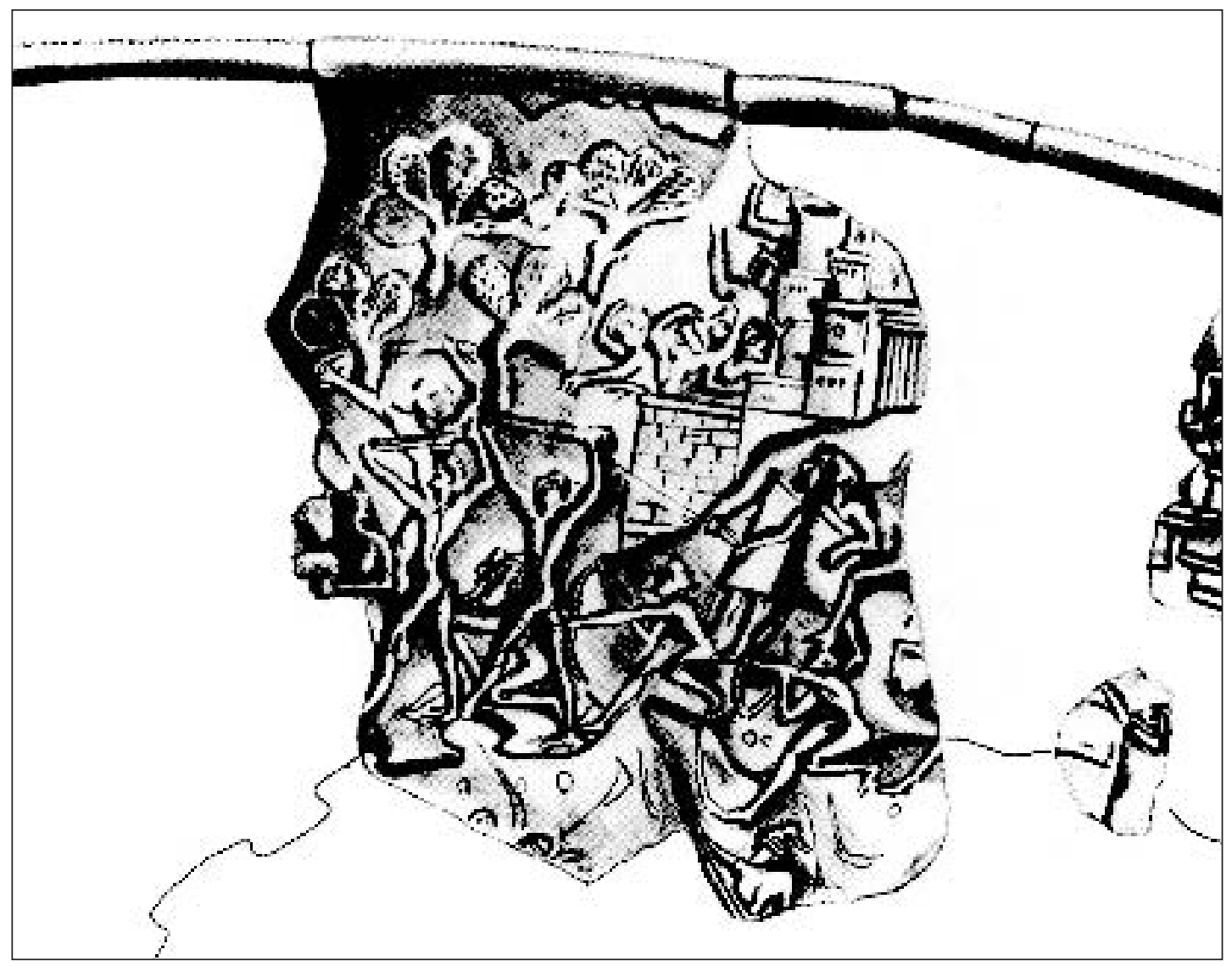

Abb. 10 Sog. ,Belagerungsrhyton' aus Mykene, Ausschnitt (nach A. SAKellariou, RA (1971), 6, Abb. 5; Zeichnung: K. Iliakis)

${ }^{36} \mathrm{Zu}$ Pfeil und Bogen als frühägäische Waffe siehe bes. BuchHOLZ, Op. cit. (Anm. 34), 1-58; Idem, Pfeilspitzen. Weitere Beobachtungen, AA (1976), 1-13.

37 E. Vermeule, Greece in the Bronze Age, Chicago 1964, 103 zu Abb. 20a. Siehe ferner W. E. STevenson, The Pathological Grotesque Representation in Greek and Roman Art, Ann Arbor 1980.

38 A. SAKellariou, La scène du «siège» sur le rhyton d'argent de Mycènes d'après une nouvelle reconstitution, RA (1975), 195-208; V. Staïs, Das silberne Rhyton des vierten Grabes der Burg von Mykenai, AM 40 (1915),

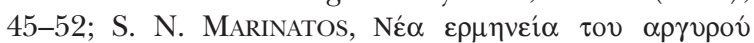

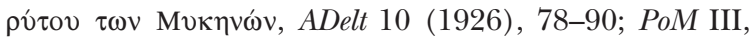
89-100, Abb. 50-56; Sмiтh, Op. cit. (Anm. 8), bes. 65-67, Abb. 84-86.

39 Siehe z.B. J. T. Hooker, The Mycenaean Siege Rhyton and the question of Egyptian influence, AJA 71 (1967), 269-281. Eine Synopse ausgewählter Deutungsversuche bieten Sakellariou, Op. cit. (Anm. 38), 205f., sowie DöHL, Op. cit. (Anm. 18), $22 \mathrm{f}$. 
licher Populationen. Das Fehlen einer Gewandangabe, aus dem wir keineswegs auf ,barbarische Nacktheit schließen sollten, läßt sich in unterschiedlicher Konsequenz in allen Figurengruppen dieses kleinformatigen Reliefbildes feststellen; und selbst ein Erkennen des ägyptischen Antagonismus von ,Ordnung und Chaos" in der Gesamtkomposition will uns nicht so recht gelingen, betrachten wir die keineswegs geordneter auftretenden Stadtverteidiger. ${ }^{40}$

Vorsicht ist in der Forschung dabei geboten, aus dem modernen Drang nach Konkretismus jedes ausgeprägtere Gesicht der ägäischen Bildkunst als exotische Besonderheit interpretieren zu wollen, was wohl nur veranschaulicht, wie wenig geläufig uns nach wie vor das ägäische ,Menschenbild' selbst ist. Jedenfalls berechtigt uns heute nichts zu Urteilen wie jenem von Friedrich Matz aus dem Jahre 1957: „Für die Merkmale der Rassetypen hatten die Minoer überhaupt ein feines Auge. “41 Insbesondere die

${ }^{40}$ R. Schulz, Remarks on the composition of hunting and battle scenes on the chest of Tutankhamun, in: S. Sherratt (Hrsg.), Proceedings of the First International Symposium 'The Wall Paintings of Thera', 30 August-4 September 1997, I, Athen 2000, bes. 261-263; S. C. HeInZ, Die Feldzugsdarstellungen des Neuen Reiches. Eine Bildanalyse, Wien 2001, 210-213, 225; S. SCHOSKE, Erschlagen der Feinde: Ikonographie und Stilistik der Feindvernichtung im alten Ägypten, Ann Arbor 1994, (non vidi). Vgl. jedoch die von L. Morgan in den Miniaturfriesen von Thera erkannte Gegenüberstellung des friedlichen und des gefahrvollen Lebens: MORGAN, Op. cit. (Anm. 16), 155-165; Eadem, Theme in the West House paintings at Thera, Archaiologiki Ephimeris (1983), bes. 104f.; J. BorCHHARDT, Ästhetische Betrachtungen zur Topik und Ikonographie der Stadt im Frieden und im Krieg in Literatur und Kunst, Lykia 1 (1994), 15-36.

41 F. Matz, Kreta, Mykene, Troja. Die minoische und die homerische Welt, Stuttgart u.a. 1957, 68. Noch zitiert bei BuchHolz, Op. cit. (Anm. 5), 139 Anm. 33.

42 Siehe oben (Anm. 18).

43 Diesen methodischen Konflikt betonte bereits der Anthropologe E. Fischer, Anthropologische Bemerkungen zu den Masken, in: G. KARO, Die Schachtgräber von Mykenai, München 1930, 320-331, bes. 321f.; Idem, Anthropologische Bemerkungen zu den Goldmasken aus den Schachtgräbern in Mykenai, Zeit schrift für Ethnologie 63 (1931), 207-212. So auch J. L. Angel, Human skeletons from Grave Circles at Mycenae, in: Mrlonas, Op. cit. (Anm. 14), 390. Dazu weiters die treffenden Überlegungen von G. KopcKe, Zum Stil der Schachtgräbermasken, AM 91 (1976), 1f. sog. ,Libyer-Hypothese“ von Spyridon Marinatos aus den frühen 70er Jahren in Verbindung mit den Wandbildern aus dem theräischen Akrotiri darf aus heutiger Sicht als methodischer Irrweg ad acta gelegt werden. ${ }^{42}$

Gerade die bildliche Darstellung eines Gesichtsprofils mit seinen physiognomischen Spezifika darf nicht a priori gleichgesetzt werden mit einem tatsächlichen, einheitlichen, ,kollektiven' frühägäischen Gesichtsprofil ${ }^{43}$ dessen Existenz durchaus hinterfragt werden muß. Forensische Rekonstruktionen frühägäischer Schädel führen zu unserer großen Freude Individuen, die ansonsten ,nur' aus dem archäologischen Befund bekannt sind, zwar aus der ,anonymen Gesichtslosigkeit‘ einer Epoche heraus ${ }^{44}$ eine methodische Rückversicherung, wie sie im Falle der Elektronmaske aus Schachtgrab $\Gamma$ in Mykene $^{45}$ und einer Weichteilergänzung des Schädels ihres Besitzers, des Individuums $\Gamma 55$, lediglich theoretisch möglich wäre, wird m.E. auch hierbei und 8. DNA-Analysen von altägäischem Knochenmaterial beispielsweise erbrachten bisher leider noch keine ausreichenden Argumente für eine Klärung dieser Frage. Siehe T. A. Brown, K. A. Brown, Ch. E. Flaherty, L. M. Little, A. J. N. W. Prag, DNA analysis of bones from Grave Circle B at Mycenae: A first report, BSA 95 (2000), 115-119.

${ }^{44}$ Zur Weichteilrekonstruktion humaner Schädel aus dem bronzezeitlichen Griechenland siehe bes. J. H. Musgrave, R. A. H. Neave, A. J. N. W. Prag, E. SakelLARAKIS, J. SAKEllarakis, The priest and priestess from Archanes-Anemospilia: Reconstructing Minoan faces, BSA 89 (1994), 89-100; J. H. Musgrave, R. A. H. Neave, A. J. N. W. Prag, Seven faces from Grave Circle $\mathrm{B}$ at Mycenae, BSA 90 (1995), 107-136; J. PraG, R. NeAve, Making Faces. Using Forensic and Archaeological Evidence. London 1997, bes. 105-156, mit Farbtaf. VIII-IX; J. Prag, The technique of Facial Reconstruction, in: Minoans and Mycenaeans. Flavours of their Time, National Archaeological Museum, 12 July-27 November 1999, Athen 1999, 218f.; D. WeSTON et. al., Report on two skeletons from tomb 132 at Armenoi, Rethymnon,

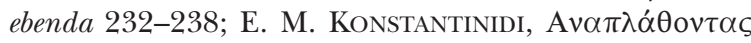

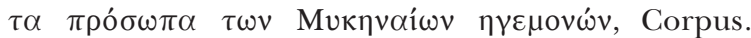

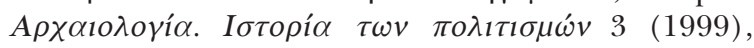
12-19.

${ }^{45} \mathrm{Zu}$ dieser Gesichtsmaske siehe bes. Mylonas, Op. cit. (Anm. 14), 76 Taf. 60a und Farbtaf. XII oben (zum Grabbefund 43 ff. mit Abb. 5); Idem, Mycenae and the Mycenaean Age, Princeton 1966, 102, 109, Abb. 97; BIESANTZ, Op. cit. (Anm. 14), 15f., Taf. 15 oben; Blegen, Op. cit. (Anm. 14), 245f., Taf. 62.3; KOPCKe, Op. cit. (Anm. 43), 4-6, Taf. 1.1. 
bestenfalls eine Frage des Ermessens bleiben müssen. ${ }^{46}$ Eine adäquate Annäherung an ein minoisches oder mykenisches Menschenbild, welches letztendlich IM Kopf entsteht, vermögen solche vermeintlichen ,Realismen“ bislang in keiner Weise zu bestätigen.

Wie auch immer der Weg ikonographischer Vermittlung von der Erscheinung zur Darstellung menschlicher Physis verlaufen sein mag, die altägäische figurale Bildkunst zeugt von der heterogenen Natur dieses Prozesses. Da die ikonische Definition eines homogenen, standardisierten frühkretischen Menschenbildes, was Physiognomie, Gesichtszüge, Körperproportionierung, aber auch Frisur, Gewandung, Schmuck und andere diagnostische Merkmale und Kennzeichnungen betrifft, in der minoischen

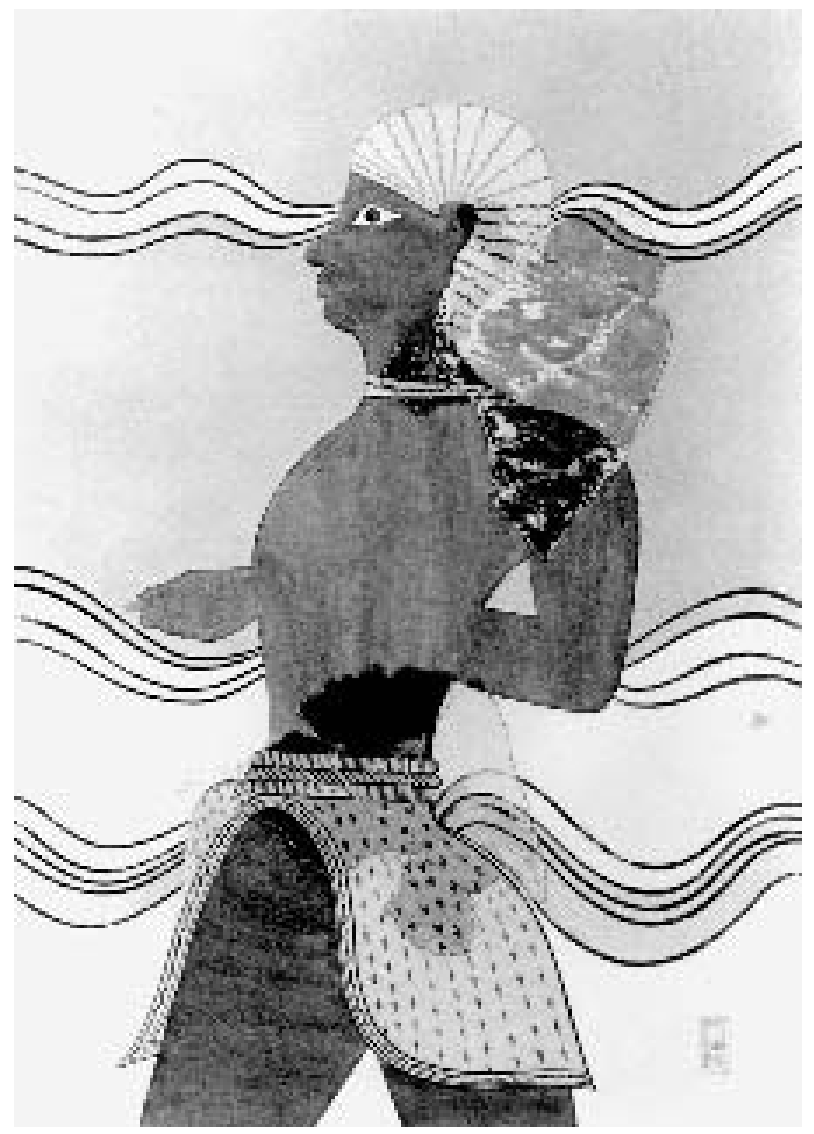

Abb. 11 Freskofragment aus Pylos

Rekonstruktion von P. de Jong (nach M. L. LANG, The Palace of Nestor at Pylos in Western Messenia II. The Frescoes, Princeton 1969, Taf. 129 rechts)

46 Dazu Musgrave, Neave, Prag, Op. cit. (Anm. 44), bes. 119f., Abb. 7-8; Taf. 16a-b; 18c; Prag, NeAVE, Op. cit. (Anm. 44), 134f., Abb. 18-20, Farbtaf. VI unten. Daß die Elektronmaske kein Porträt des Bestatteten im strengen Sinne darstellt, ja aus methodischen Gründen gar nicht darzustellen braucht, und "when it comes to
Ikonographie nur in verhältnismäßig geringem Maße abgeklärt oder überhaupt intendiert erscheint und die altägäische Bildwelt nahezu durchwegs darauf verzichtete, Fremde durch eindeutige Realien unmißverständlich als Nicht-Ägäer bildlich zu determinieren, müssen wir annehmen, daß eine differenzierende Darstellung des ,Selbst' und des ,Anderen auf ethnischer Basis, d.h. eine Bildwürdigkeit von ,Fremden` in der minoischen Ikonographie generell

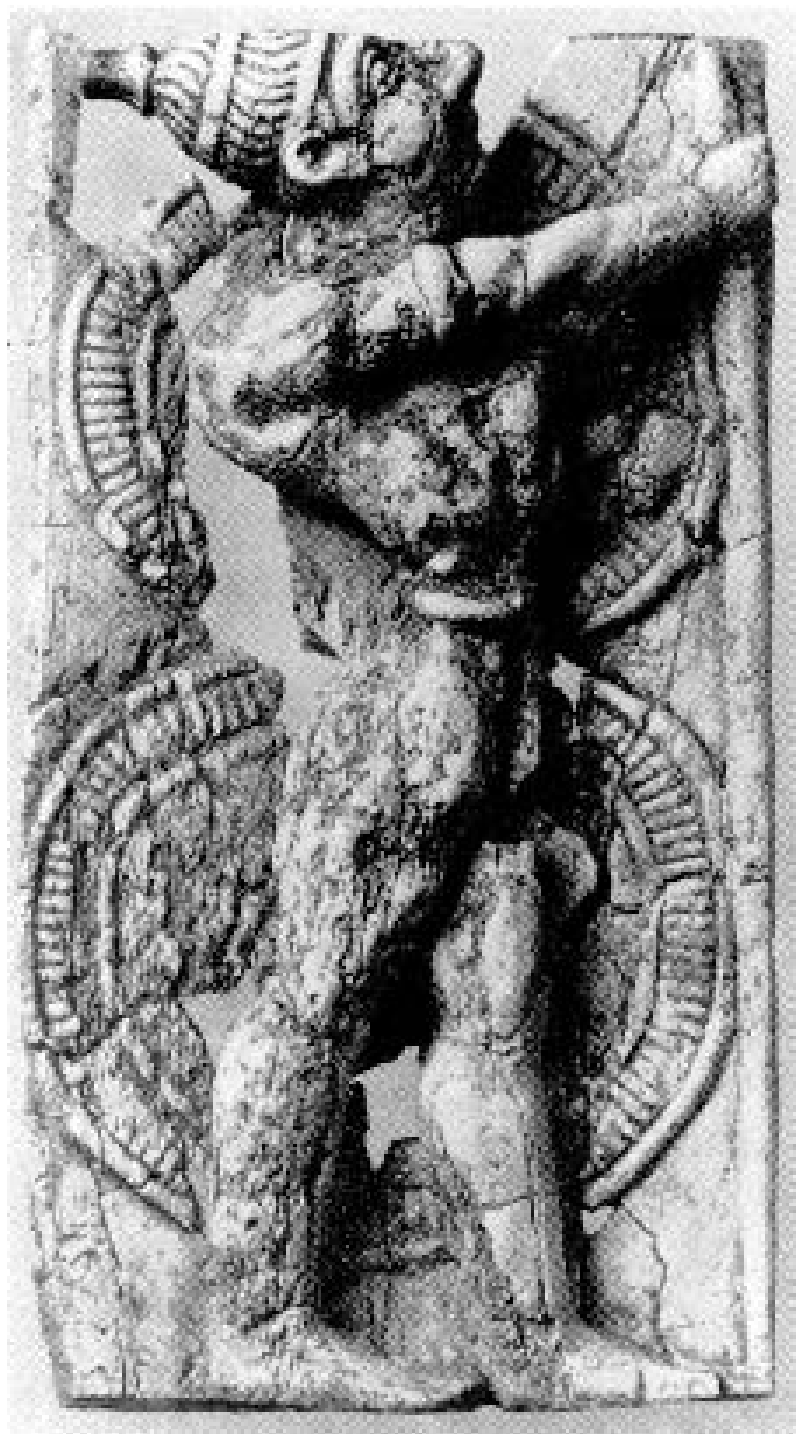

Abb. 12 Elfenbeinplakette aus Delos

(nach J.-C. Poursat, Les ivoires mycéniens. Essai sur la formation d'un art mycénien, Athen 1977, Taf. XIV,1)

details the two do not match" (ebenda, 134), anerkannten sehr offen auch die Autoren. Vgl. weiters die Beurteilung des Individuums nach DNA-Analyse als "possible female“: Brown, Brown, Flaherty, Little, Prag, Op. cit. (Anm. 43), 117f. mit Tabelle 1. 
nicht gegeben war. Das Fragezeichen im Titel dieses Artikels erweist sich somit als begründet.

Die Möglichkeiten einer klaren Definition eines fremdländischen Erscheinungsbildes mit Hilfe eines ausgebildeten ikonographischen, Vokabulars veranschaulicht uns hingegen eine schwarzhäutige Figur in einem spätmykenischen Wandbild aus dem messenischen Pylos $^{47}$ (Abb. 11), mit ,un-ägäischer Kopftracht ${ }^{48}$ und ,minoisierendem ' Schurz, ${ }^{49}$ die Teil einer Figurenreihe, bestehend aus weiteren Trägern dieser wohl ägyptischen Kopfbedeckung und in Raubtierfelle gekleidet,$^{50}$ bildete; - aller Wahrscheinlichkeit nach also eine Gruppe von Ägyptern, ${ }^{51}$ darunter auch mindestens ein Nubier. Die

47 M. L. Lang, The Palace of Nestor at Pylos in Western Messenia II. The Frescoes, Princeton 1969, bes. 41-43, 61, 94 (59 H nws), Taf. 129 rechts. Da ein weiteres Fragment eines ähnlichen dreiteiligen Gürtels nachgewiesen ist, vermutete LANG, Op. cit. 94, einen zweiten Schwarzafrikaner in diesem Wandbild. Siehe weiters S. A. IMMERWAHR, Aegean Painting in the Bronze Age, University Park PA - London 1990, 118, 197 (Py Nr. 7); S. Hiller, Zur Rezeption Ägyptischer Motive in der Minoischen Freskenkunst, ÄEL 6 (1996), 90-92 mit Abb. 35-38.

48 Eine von der ägyptischen Tracht des Sem-Priesters in die pylische Gewandung übernommene Kopfbedeckung möchte hier HAIDER, Op. cit. (Anm. 2, 1996), 138, erkennen, der folglich von einer ,ethnisch gemischten' Prozession von Pyliern und (einem) Schwarzafrikaner(n) spricht. Da besagte Kopfbedeckung bislang ein Unikat in frühägäischen Trachtdarstellungen bildet, darf sie m.E. problemlos als Fremdelement verstanden werden.

49 LANG, Op. cit. (Anm. 47), 61, spricht von einem minoischen Schurz, der in den Wandbildern von Pylos v.a. bei ,minoisierenden` Themen begegnet. Bei seinem Auftreten in Verbindung mit einem Afrikaner könnte möglicherweise Langs Bemerkung, daß Schwarze in Pylos wohl „under Minoan auspices and never, went native“" aufzufassen sein dürften, hilfreich für unser Verständnis sein.

${ }^{50}$ Zum Tierfell als Bekleidung von - aus mykenischer Sicht - Fremden und Wilden siehe M. Lang, Pylos Polytropos, Minos 20-22 (1987), bes. 333, 340; N. Yalouris, Ein Schlachtengemälde im Palast des Nestor, AM 104 (1989), 41-48, bes. 43f. Vgl. WaChSMAnn, Op. cit. (Anm. 2), 46, über die Darstellung von Schwarzafrikanern in der ägyptischen Kunst der 18. Dynastie: „Nubian blacks are generally dressed in animal skin loincloths. "

51 Siehe zu dieser Deutung bes. E. SAPOUNA-SAKELLARAKI,

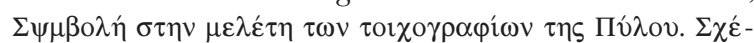

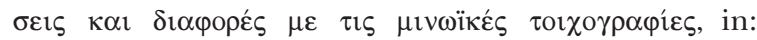

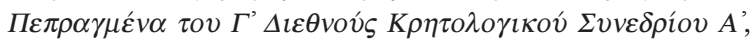
Athen 1973, 300f., Taf. 82-83; Eadem, Op. cit. (Anm. 15), 501, Taf. 156a; Hiller, Op. cit. (Anm. 47), 90-92, Abb. 35-38; N. LuRZ, Der Einfluß Ägyptens, Vorderasiens und Kretas auf die Mykenischen Fresken. Studien zum Ursprung der Frühgriechischen Wandmalerei, Frankfurt am Main 1994, 110-112.
Frage nach der Identität und ethnischen Zugehörigkeit der Gegner in mykenischen Kampfdarstellungen kann hier nicht weiter verfolgt werden. ${ }^{52}$ Dies würde uns m.E. jedoch geographisch aus dem inner-ägäischen oder - noch enger - dem helladischen Raum kaum herausführen. Daß in der frühägäischen Ikonographie aber physiognomische Auffälligkeiten wie eine wulstige Nase noch keine ausreichende Kennzeichnung eines Angehörigen einer fremden Ethnie ausmachen mussten, ${ }^{53}$ veranschaulicht sehr gut der unzweifelhaft mykenische Krieger mit Keilerzahnhelm und Achter-förmigem Schild auf einer mykenischen Elfenbeinplakette aus $\operatorname{Delos}^{54}$ (Abb. 12).

${ }^{52} \mathrm{Zu}$ mykenischen Kampfszenen siehe allg. DöHL, Op. cit. (Anm. 18), 21-32; V. STÜRMER, Zur Ikonographie des Kampfes auf dem Siegelring CMS I, Nr. 16, OpAth 14 (1982), 111-118; R. LAFFINEUR, Iconographie mycénienne et symbolisme guerrier, Art et Fact 2 (1983), 38-49; Idem, Iconographie minoenne et iconographie mycénienne à l'époque des tombes à fosse, in: P. DARCQUE, J.-C. Poursat (Hrsg.), L'iconographie minoenne. Actes de la table ronde d'Athènes (21-22 avril 1983), BCH Suppl. XI, Paris 1985, 245-266; LANG, Op. cit. (Anm. 50), 333-341, bes. 335; Yalouris, Op. cit. (Anm. 50), 41-48; S. HiLLER, Scenes of warfare and combat in the arts of Aegean Late Bronze Age. Reflections on typology and development, in: R. LAFFInEUR (Hrsg.), POLEMOS. Le contexte guerrier en Égée à l'âge du Bronze, Actes de la 7e Rencontre égéenne internationale, Université de Liège, 14-17 auril 1998, Aegaeum 19, II, 1999, 319-330; L. KONTORLI-PAPADOPOULOU, Fresco fighting-scenes as evidence for warlike activities in the LBA Aegean, ebenda, 331-339.

${ }^{53}$ Aufgrund der gekrümmten, überlangen Nase wollte Evans (PoM III, 230f., Abb. 164 A; IV, 474, Abb. 400) im Stierfänger (mit ägäischem Schurz) auf einem Lentoid aus Mykene (CMS I Nr. 95) einen Anatolier erkennen. Ähnlich auch BuchHolz, Op. cit. (Anm. 5), 140 („Orientale“).

54 H. Gallet de Santerre, J. Tréheux, Rapport sur le dépôt égéen et géometrique de l'Artémision à Délos, BCH 71/72 (1947/48), 156-162, Taf. XXV (auf S. 160f. werden hethitische Stilzüge bei der Gesichtsgestaltung in Erwägung gezogen); J.-C. Poursat, Les ivoires mycéniens. Essai sur la formation d'un art mycénien, BÉFAR 230, Athen 1977, 157, Taf. XIV.1. H. KANTOR, Ivory carving in the Mycenaean period, Archaeology 13 (1960), 23 mit Abb. 20, wies auf den rein ägäischen Stil des Elfenbein-Kriegers hin, wofür die übertriebenen Muskeln und die äußerst schmale Taille als Argumente herangezogen werden können. Im Gegensatz dazu stünden die ,mykenisch-orientalischen' Formen auf zahlreichen Spiegelgriffen. Für eine Deutung als Ägäer entschied sich hier auch BuchHolz, Op. cit. (Anm. 5), 141f., Anm. 47. 


\section{ZuM SOG. ,CAPTAin OF THE Blacks ${ }^{6}$ AUS KNOSSOS}

Betrachten wir nach diesen Überlegungen ein weiteres vermeintlich klares Beispiel für Afrikaner in der minoischen Bildkunst. Als eindeutiges und m.W. bislang noch nie in Zweifel gezogenes Kriterium für die ethnische Charakterisierung von Afrikanern gilt die grauschwarze Inkarnatsfarbe im prominenten Beispiel des sog. ,Captain of the Blacks ${ }^{65}$ (Abb. 13 und 14). Dieses bildet einen Freskenfundkomplex fortgeschrittenen spätminoischen Stils ${ }^{56}$ aus den oberen Schuttschichten eines Hauses in Knossos, und sein originaler Zusammenhang ist nicht mehr bestimmbar. Auf zwei Fragmenten nachgewiesen laufen zwei Schwarzhäutige - mit ägäischer Frisur, ${ }^{57}$ ägäischer Tracht $^{58}$ und wohl auch ägäischer Bewaffnung ${ }^{59}$ ver-

55 Dazu v.a. PoM II, 755-757 mit Farbtaf. XIII; IV, 886-888, Abb. 869; J. D. S. Pendlebury, The Archaeology of Crete, New York 1939, 200f.; H.-G. BuchHolz, V. KARAGEORGHIS, Altägäis und Altkypros, Tübingen 1971, 80f., Taf. 1051; F. SCHACHERMEYr, Die minoische Kultur des alten Kreta, Stuttgart u.a. 1964, 275, Abb. 141; BuchHolz, Op. cit. (Anm. 5), 140f.; HAIDER, Op. cit. (Anm. 5, 1979), bes. 291 mit Anm. 33; Idem, Op. cit. (Anm. 5, 1984), 187; Idem, Op. cit. (Anm. 4, Darmstadt 1988), bes. 99 Anm. 82; Idem, Op. cit. (Anm. 2, 1996), 138f., Abb. 1; IMMERWAHR, Op. cit. (Anm. 47), 96. 176 (Kn Nr. 27); REHAK, Op. cit. (Anm. 2), 45 mit Abb. 7; S. Hiller, ,The Captain of the Blacks'. Zur Bildthematik eines Freskofragments aus Knossos, in: S. BÖHM, K.-V. vON EICKSTEDT (Hrsg.), I⿶AKH. Festschrift für Jörg Schäfer zum 75. Geburtstag am 25. April 2001, Würzburg 2001, 31-36.

56 So etwa auch C. F. Hawke SMITH, The Knossos frescoes: A revised chronology, BSA 71 (1976), 74. Trotz der Hinweise bei J. Driessen, The Minoan Hall in Domestic Architecture on Crete: To be in vogue in LM IA, Acta archaeologica Lovaniensia 21 (1982), 46, 68f., Anm. 123 (,... no mention is made of LM II or LM IIIA sherds") und J. Driessen, C. MACDOnAld, Some military aspects of the Aegean in the Late 15th and early 14th century, BSA 79 (1984), 52, Anm. 24, wo sich die Angabe „SM $I B$ " wohl auf das ,House of the Frescoes" bezieht, darf beim heutigen Kenntnisstand aufgrund stilistischer Kriterien m.E. eine Datierung vor SM II ausgeschlossen werden. Vgl. nun J. Driessen, C. F. Macdonald, The Troubled Island. Minoan Crete before and after the Santorini Eruption, Aegaeum 17 (1997), 56: „From the pottery in the Stratigraphical Museum it is clear that the site (not the house) was in continuous use from at least $M M$ III/LM IA to LM IIIA2“.

57 Zum kurzen Haarschnitt im fortgeschrittenen Spätminoikum siehe bes. Marinatos, Op. cit. (Anm. 35), 1-15.

58 Zum Schurz der Figuren siehe bes. E. SAPOUNA-SAKEL-

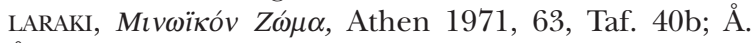
ÅkERSTRÖM, Some pictorial vase representations from the mainland in Late Helladic times, OpAth 1 (1953), sehen - innerhalb einer vermutlich größeren Gruppe von Kriegern, von denen zumindest einer rothäutig ist und somit unzweifelhaft als Ägäer angesprochen werden darf. ${ }^{60}$ Der weißliche Hintergrund des einen erhaltenen dunklen Kopffragmentes veranschaulicht uns, daß wir eine Reihe von mindestens drei Kriegern im Laufschritt im Rahmen eines längeren Bildfrieses mit wechselndem Hintergrundkolorit vor uns haben. ${ }^{61}$ Über die ursprünglich sicherlich umfangreichere Ikonographie dieses Wandfrieses kann nichts Gesichertes ausgesagt werden, ${ }^{62}$ doch sind uns Reihen mehr oder weniger uniform geschilderter Krieger sowohl in der älteren minoischen $^{63}$ als auch in der nur etwas jüngeren Bildkunst des mykenischen Festlandes ${ }^{64}$ bezeugt. Durch nichts wird nahegelegt, daß es sich bei der zweifellos ägäi-

15-17 mit Abb. 4; F. SCHACHERMEYR, Das Keftiu-Problem, ÖJh 45 (1960), 54, Abb. 40; ReHAK, Op. cit. (Anm. 2), bes. 45, Abb. 7. Zum getragenen Schmuck vgl. Younger, Op. cit. (Anm. 22), bes. 262-269.

${ }_{59} \mathrm{Zu}$ Speeren in der Bildkunst siehe H. Müller-KarPe, Zur spätbronzezeitlichen Bewaffnung in Mitteleuropa und Griechenland, Germania 40 (1962), 255-287; R. A. J. Avila, Bronzene Lanzen- und Pfeilspitzen der griechischen Spätbronzezeit, Prähistorische Bronzefunde V, 1, München 1983, 118-130; O. Höckmann, Lanze und Speer, in: H.G. BuchHolz, Kriegswesen, Teil 2, ArchHom E, 2, Göttingen 1980, 275-319, bes. 288, Abb. 73; Idem, Lanze und Speer im spätminoischen und mykenischen Griechenland, JbRGZM 27 (1980), 13-158.

${ }^{60}$ Vgl. jedoch die von Hiller, Op. cit. (Anm. 55), 36, in Erwägung gezogene Deutung der „merkwürdigen Kopfbedeckung" als Hörnerhelm von Schardana-Kriegern, bei denen es sich folglich um „aus Ägypten entliehene fremdländische Söldner in kretischen Diensten " handeln könnte.

${ }^{61}$ Zur Kompositionsweise vgl. die wohl etwa zeitgleichen oder nur wenig jüngeren Beispiele aus Agia Triada: P. Militello, Haghia Triadha I. Gli affreschi, Padua 1998, 132-167, Taf. 9-16, Farbtaf. I und L; CH. R. LonG, The Ayia Triadha Sarcophagus. A Study of Late Minoan and Mycenaean Funerary Practices and Beliefs, SIMA XLI, Göteborg 1974, passim, Taf. 6, 15, 19, 30-31; S. MARInatos, M. Hirmer, Kreta, Thera und das mykenische Hellas ${ }^{2}$, München 1973, Farbtaf. XXX-XXXIII.

62 Vgl. den Rekonstruktionsvorschlag von Hiller, Op. cit. (Anm. 55), 34-36, als sogenannte ,Wagenläufer" mit Stab, d.h. ein Wagengespann begleitende Gefolgsleute.

${ }^{63}$ Siehe die Reihe schreitender Krieger im Südfries des ,West-Hauses“ von Akrotiri, Thera (Anm. 77) und das Fragment eines Steinreliefgefäßes aus Epidavros: A. SAKELlariou, Scène de bataille sur un vase mycénien en pierre?, RA (1971), 3-14; Eadem, Op. cit. (Anm. 8), 532-534, Taf. 180; J. A. Sakellarakis, Mycenaean stone vases, SMEA 17 (1976), $184 f$.

${ }^{64}$ Vgl. unten (Anm. 77-80). 


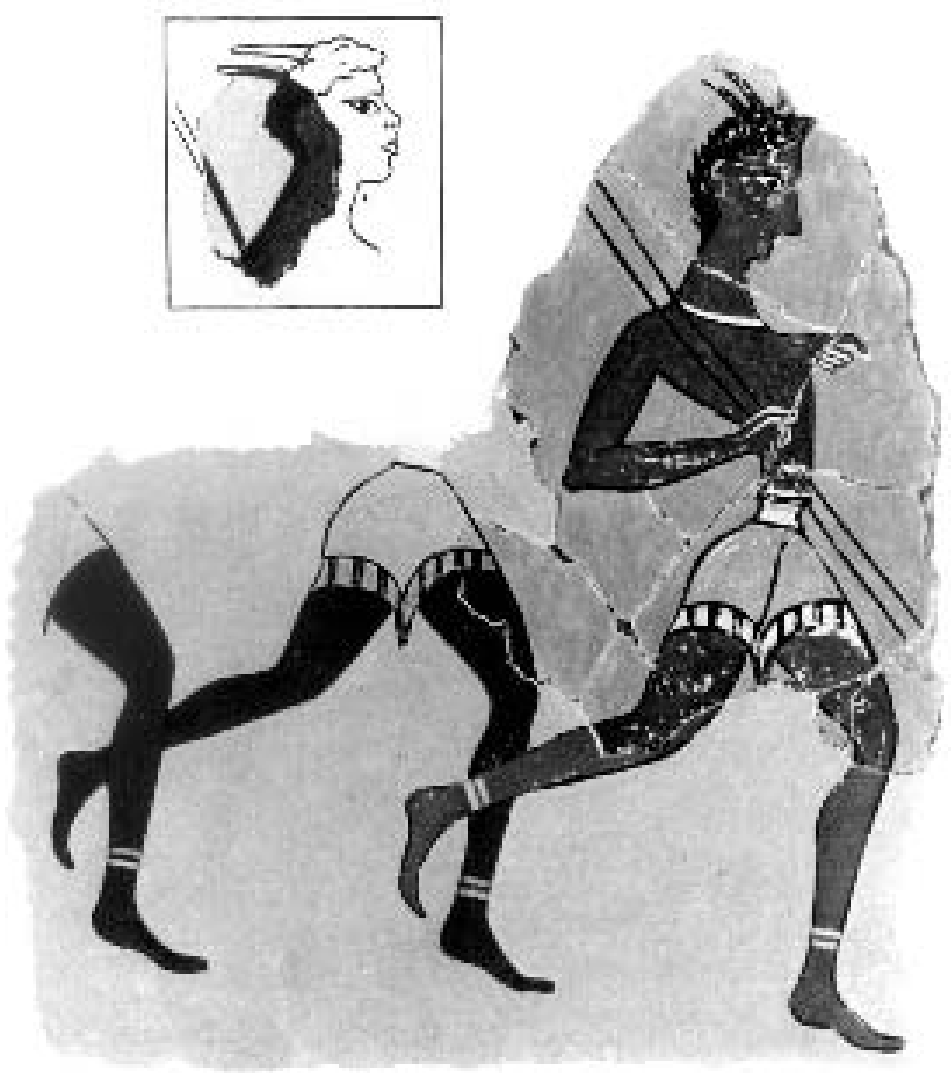

Abb. 13 ,Captain of the Blackss“ nach A. Evans (nach PoM IV, 886, Abb. 869)

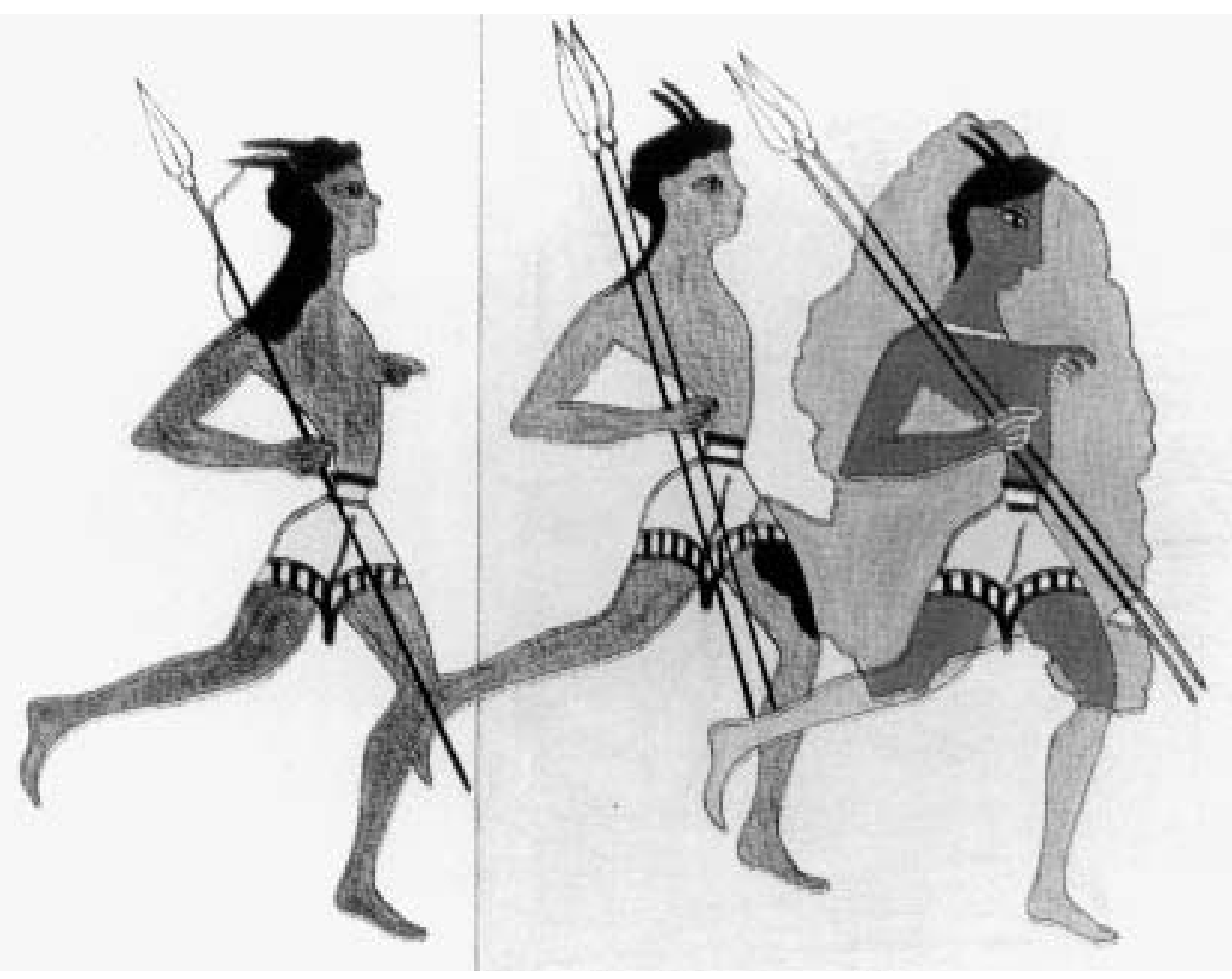

Abb. 14 ,Captain of the Blacks' nach M.A.S. CAMERON

(nach D. Evely [Red.], Fresco: A Passport into the Past. Minoan Crete through the Eyes of Mark Cameron, Athen 1999, Abb. S. 191) 
schen ,Rothaut' um einen Anführer oder den namengebenden ,Captain' handelt. ${ }^{65}$ Das ,barbarisch' anmutende Zacken-, Hörner- oder Federpaar im Haar begegnet uns nicht nur am Kopf des einen Schwarzhäutigen, sondern auch dem des rotbraunen Ägäers, kann also schwerlich als Zeichen unminoischer, ,barbarischer", ja ,tierischer" Wildheit verstanden werden und hilft uns bei der Beurteilung nicht weiter. ${ }^{66}$ Es ist somit evident, daß sich diese Schwarzhäutigen vom Bild des Ägäers ikonographisch allein durch die Wahl des Inkarnatskolorits unterscheiden.

Assimilierte, d.h. in bezug auf Frisur, Tracht und Bewaffnung gänzlich akkulturierte Schwarzafrikaner im spätminoischen Heer, die entweder als Besonderheit oder auch als Selbstverständlichkeit Bildwürdigkeit erlangt hätten, könnte man als Arbeitshypothese durchaus akzeptieren. Der prononcierte, von A. Evans (Abb. 13) wie auch M. A. S. Cameron (Abb. 14) suggestiv, à l'Africaine ergänzte Kopf des zweiten Schwarzhäutigen ${ }^{67}$ besitzt hingegen keinerlei ikonographische Unterstützung im gesamten bislang bekannten Denkmälerspektrum der Frühägäis und muß als Beurteilungskriterium ausscheiden. Und so werden wir wohl nie endgültig erfahren, ob auch die Gesichtszüge der Schwarzhäutigen dieses Wandbildes wie auch ihre übrige Erscheinung dem minoischen sogenannten ,Cap-

${ }^{65}$ Siehe z.B. PoM IV, 886: „a Minoan officer" in einem Wandbild, das, so PoM II, 756, auf die minoische Eroberung und koloniale Expansion in Richtung Afrika rückschließen ließe. Der Vollständigkeit halber muß der weiße Halsschmuck des Rothäutigen erwähnt werden, der zumindest beim Nackenfragment des einen Schwarzhäutigen nicht (mehr?) vorhanden ist. Dazu, daß es sich bei Halsketten von Ägäern um keine militärischen Rangabzeichen handeln dürfte, siehe Kilian-Dirlmeier, Op. cit. (Anm. 24, 1985), bes. 207 mit Anm. 44.

66 Unklar bleibt nach wie vor, ob es sich hier um aufgesetzte Hörner, eine spezielle Frisur oder - m.E. wohl am ehesten - um Federn als Kopfschmuck handelt. Vgl. die Kopfzier der beiden Akrobaten mit minoischem Schurz auf einem Siegel aus Knossos (PoM IV, 501f., Abb. 443), den Ägäer im sog. ,Afrikaner-Fresko“ aus Thera (oben Abb. 5 mit Anm. 15-16) sowie den Akrobaten mit komplexerem Kopfschmuck vor einer Palme auf einem Freskofragment aus Tell el-Dabca: Bietak, Op. cit. (Anm. 3), 49f., Taf. 17B; Idem, Connections between Egypt and the Minoan world. New results from Tell el-Dabca/Avaris, in: DAvIES, ScHOFIELD, Op. cit. (Anm. 1), 24, Taf. 3.1; Rekonstruktion tain' entsprachen - kretischen Köpfen also, die, wie wir zuvor gesehen haben, in der Ikonographie in der Regel schwarzes, gewelltes oder oft krauses Haar, gewölbte Lippen und wulstige, abgeknickte oder Stupsnasen besitzen. ${ }^{68}$ Nach dieser - zugegebenermaßen tendenziösen - Verunsicherung soll hier eine andere Erklärung des Einsatzes des ikonographischen Mittels der dunklen Hautfarbe in diesem und weiteren Beispielen zur Diskussion gestellt werden.

Es ist zunächst die ägyptische Malerei, die uns nicht nur Dunkelhäutige in großer Zahl - gemeinsam mit anderen ikonographischen Charakteristika als der dunklen Hautfarbe und teils auch durch Beischriften - unmißverständlich als Schwarzafrikaner vor Augen führt, ${ }^{69}$ sondern die daneben auch einen sehr plausiblen Grund für einen Wechsel des für Männer konventionellen roten Inkarnatskolorits kannte. Eine davon abweichende hellere, oft aber auch dunklere Hautfarbe diente dabei offensichtlich zur besseren Kenntlichmachung von einander überschneidenden Figuren und ihren Gliedern, war jedoch inhaltlich gleichbedeutend mit der normativen Rothäutigkeit der Ägypterdarstellungen. Diese Konvention wurde etwa bei Ringergruppen mit ihren vielseitigen Überlappungen erforderlich, wie in einem Wandbild aus dem Mittleren Reich in Beni Hassan $^{70}$ (Abb. 19), oder bei gestaffelt wiedergegebenen Kriegerreihen, wofür eine thebanische Grab-

bei M. BIETAK in: Pharaonen und Fremde. Dynastien im Dunkel, Ausstellungskatalog, Wien 1994, 201 (Kat. Nr. 225). Siehe allg. L. Holland, Mycenaean plumes, AJA 33 (1929), 173-205.

67 Publiziert bei Evely, Op. cit. (Anm. 21), 191 mit Abb.

68 „Die kecke Stupsnase, die verschmitzt verkniffenen Augen, die geöffneten, leicht wulstigen Lippen, die vorgeschobene Mundpartie ... "galten für BuchHolz, Op. cit. (Anm. 5), 141, als Kennzeichen eines frühägäischen Fremdenbildes.

69 R. DrenkHahn, Darstellungen von Negern in Ägypten, phil. Diss. Hamburg 1967; J. VercoutTER, The iconography of the black in ancient Egypt: From the beginning to the twenty-fifth Dynasty, in: J. VercoutTer, J. LECLANT, F. SNOWDEN (Hrsg.), The Image of the Blacks in Western Art, Lausanne 1976, 33-88; W. Helck, Die Ägypter und die Fremden, Saeculum 15 (1964), 103-114. Siehe ferner V. Karageorghis, Blacks in Ancient Cypriot Art, Houston 1988, 7-15.

70 A. GH. SHedID, Die Felsgräber von Beni Hassan in Mittelägypten, Mainz am Rhein 1994, 31, Abb. 43 sowie S. 70: „Die beiden Kontrahenten werden in zwei verschiedenen Brauntönen dargestellt, ein Mittel, das man ja auch aus Staffelreihen kennt, um die einzelnen Personen optisch besser unterscheiden zu können". 
malerei aus der Zeit Tuthmosis IV. (Abb. 15) als Beispiel dienen soll. ${ }^{71}$

In der ägäischen Bildwelt selbst sind es vor allem Gattungen mit Firnis- oder beschränktem Farbauftrag wie die Sarkophagmalerei, die uns gelegentlich eine ähnliche ikonographische Chiffre bei gereihten oder einander überschneidenden Figuren bezeugen, wie wir insbesondere auf Larnakes aus dem boiotischen Tanagra erkennen können. Wäh- rend diese Konvention alternierender Farbgebung, die sich aus der ägyptischen Bildkunst ableiten dürfte, am Beispiel in Abb. 16 Gewandung und Hautfarbe der repetitiven Figuren aus Gründen der chromatischen Vielfalt auflockert, ${ }^{72}$ erleichtert die abwechselnd rote und blauschwarze Kolorierung auf einer polychromen Larnax (Abb. 17) vor allem das Erkennen der erhobenen Arme der Trauernden im oberen Register wesentlich. ${ }^{73}$ Selbst wenn

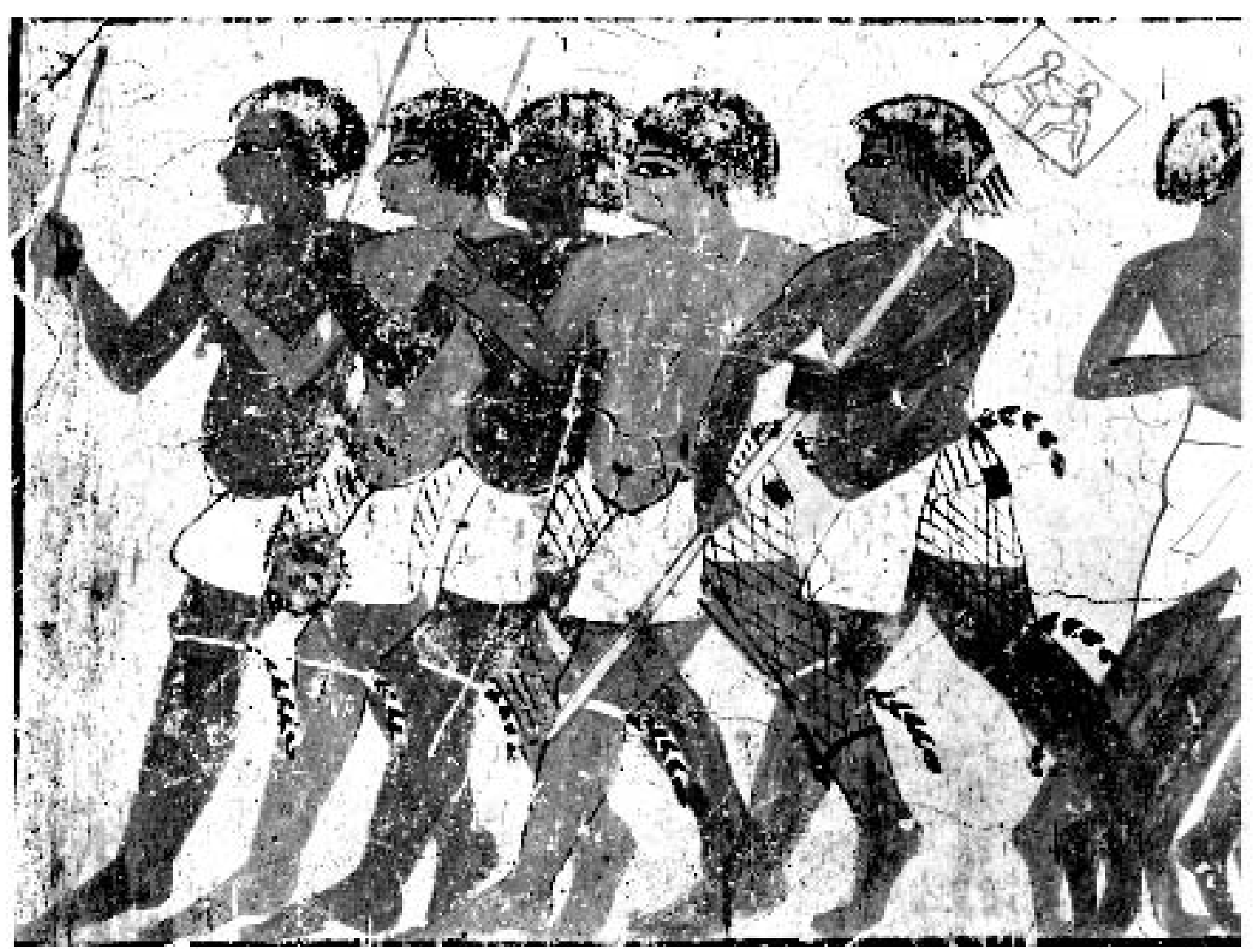

Abb. 15 Ägyptisches Wandbild aus dem Grab des Thanuny, Theben (nach A. Mekhitarian, Egyptian Painting, Genf 1978, Abb. auf S. 97)

${ }^{71} \mathrm{Zu}$ dieser Darstellung nubischer Söldner in der Grabkapelle des Militärschreibers Thanuny in Theben siehe A. Mekhitarian, Egyptian Painting, Genf 1978, Abb. auf S. 97.

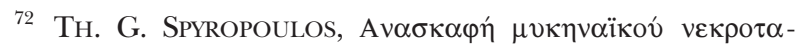

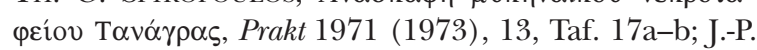
MichaUd, BCH 96 (1972), 699, 701, Abb. 267-268.

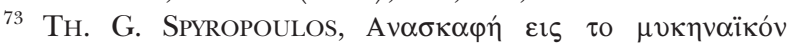

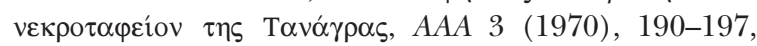

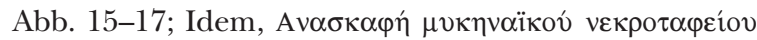
Tovórpas, Prakt 1969 (1971), 14f., Taf. 13a, 14; Idem, Mycenaean Tanagra: Terracotta sarcophagi, Archaeology 25, H. 3, Juni 1972, 206f. mit Farbabb.; G. AhlberG, Prothesis and Ekphora in Greek Geometric Art, SIMA 32,
Göteborg 1971, Abb. 66 d, 67 a-b; K. Demakopoulou, D. Konsola, Archäologisches Museum Theben. Führer durch die Ausstellung, Athen 1981, 82, Taf. 42; IMMERWAHr, Op. cit. (Anm. 47), 157f., Taf. XXII-XXIII; P. REHAK, Tradition and innovation in the fresco from room 31 in the ,Cult Center ${ }^{6}$ at Mycenae, in: R. Laffineur, J. L. Crowley (Hrsg.), EIKSN. Aegean Bronze Age Iconography: Shaping a Methodology. Proceedings of the $4^{\text {th }}$ International Aegean Conference, University of Tasmania, Hobart, Australia, 6-9 April 1992, Aegaeum 8 (1992), 49 Anm. 107. Siehe auch die Deutung der Ikonographie als, rites de passage ' bei M. BEnzI, Riti di passaggio sulla larnax dalla Tomba 22 di Tanagra?, in: V. La Rosa, D. Palermo, 


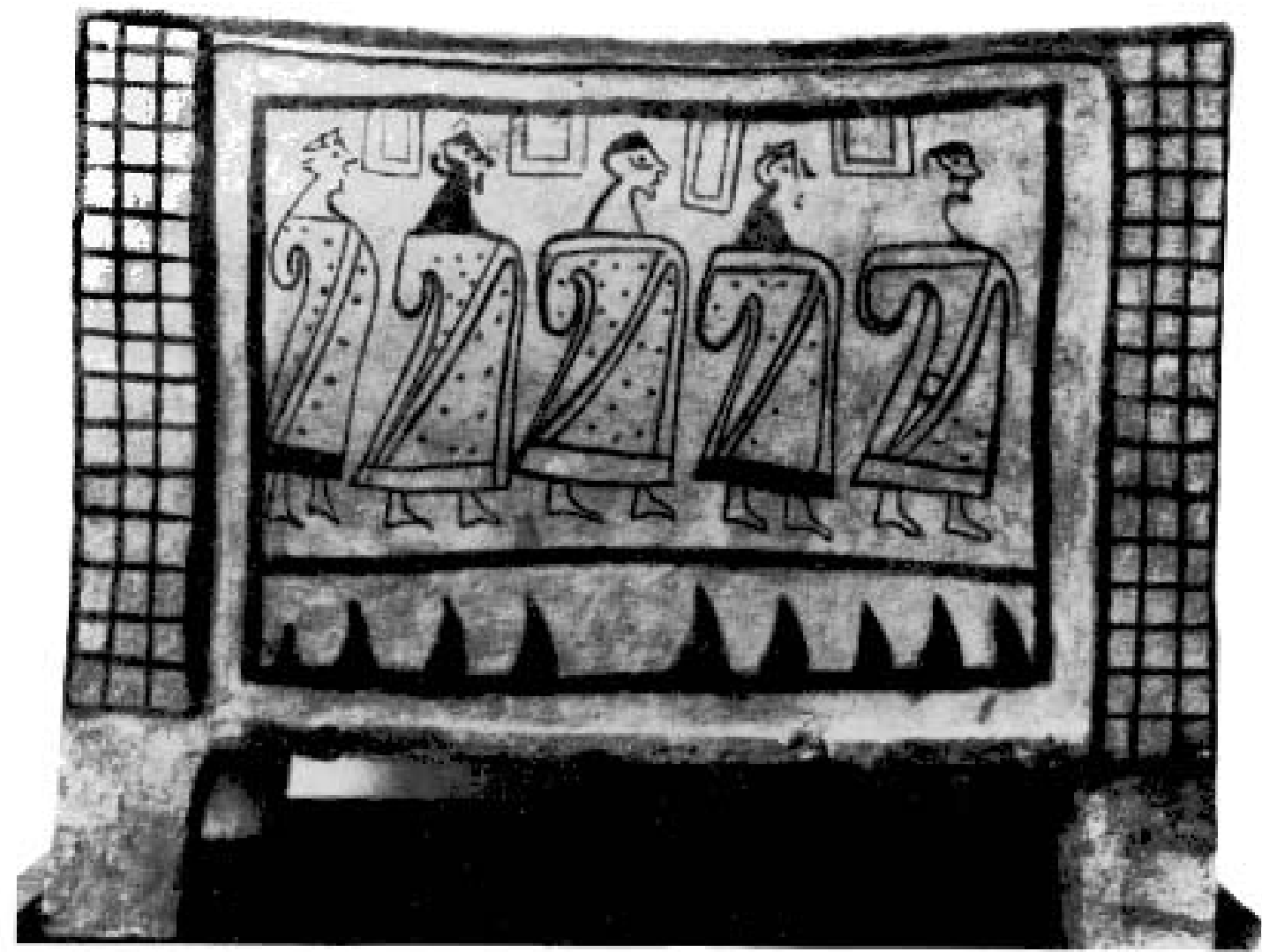

Abb. 16 Larnax aus Grab 60 in Tanagra, Boiotien (nach TH. Spyropoulos, Prakt (1971), Taf. 17a)

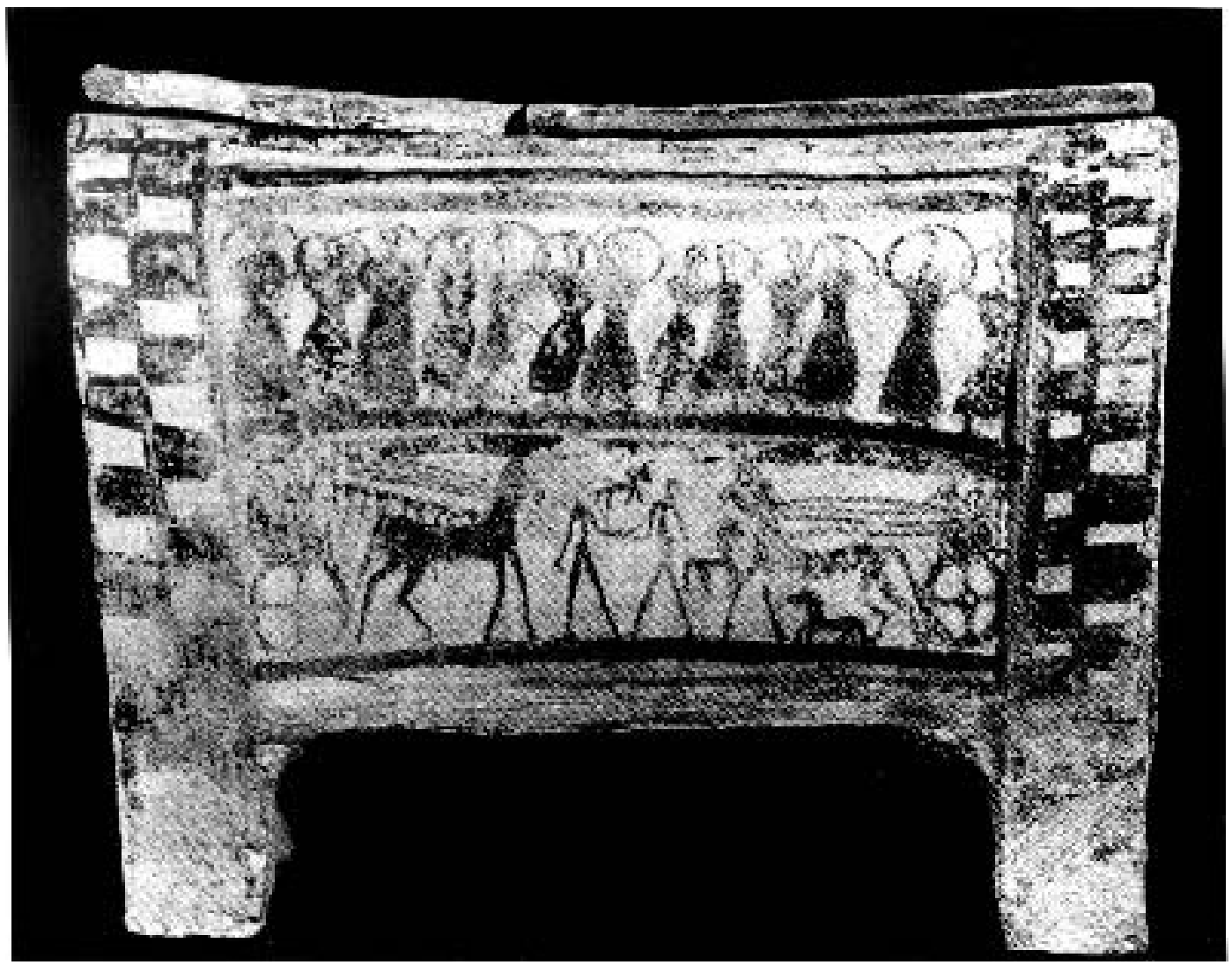

Abb. 17 Larnax aus Grab 22 in Tanagra, Boiotien

(nach K. Demakopoulou und D. Konsola, Archäologisches Museum Theben. Führer durch die Ausstellung, Athen 1981, 82, Taf. 42) 
sich ein alternierendes, nicht gegenstandsgebundenes Kolorit in der frühägäischen Stilsprache als Mittel abwechslungsreicher Variabilität und Ornamentik in vielseitiger Form charakterisieren läßt, sein Einsatz bei sich überschneidenden Figuren wie auch gestaffelten Tieren und architektonischen Fassadenteilen macht deutlich, daß wir es hier auch mit einem die Bildkomposition klärenden minoisch-mykenischen Kunstgriff zu tun haben. ${ }^{74}$

In der ägäischen Wandmalerei schließlich ist eine solche Konvention alternierenden Körperkolorits bislang zwar nur in geringer Zahl, aber immerhin in einer Reihe ikonographisch konsistenter Beispiele vor allem der Spätzeit nachgewiesen. Ein Freskofragment aus Tiryns (Abb. 20) präsentiert hinter einer konventionell rothäutigen Figur eine zweite mit ungewöhnlicher, gelber Gesichtsfarbe, die Gerhard Rodenwaldt mit seiner Deutung als „ausländischer Sklave" sicherlich unzureichend erklärte ${ }^{75}$ Ein in seiner Farbgebung, Komposition und wohl auch Problematik vergleichbares Gegenstück ist aus Orchomenos bekannt ${ }^{76}$ (Abb. 21), und wir werden hierbei folglich nicht a priori an ein inhaltliches oder gar ethnisches Unterscheidungskriterium denken, als vielmehr die zuvor genannte Konvention zur differenzierenden bildlichen Klärung der gestaffelten oder bloß gereihten Figuren als Grund für die chromatische Variabilität und die Wahl einer ,wertfreien' zweiten - manchmal helleren, manchmal dunkleren - Hautfarbe annehmen dürfen. Einschränkend bleibt es aber ein Faktum, daß bei ande-

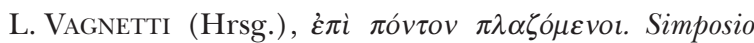
italiano di Studi Egei (dedicato a Luigi Bernabò Brea e Giovanni Pugliese Carratelli), February 18-20, 1998, Rom 1999, 215-233.

74 Bereits A. von SALIS, Die Kunst der Griechen, Leipzig 1919, 19, betonte in Hinblick auf die fortgeschrittene spätbronzezeitliche Bildkunst ,in der Anordnung der Farben jene rhythmische Regelmäßigkeit, die rein dekorativ zu verstehen ist". Zu dem auf demselben Prinzip basierenden frühägäischen ,Zahnmuster‘ siehe bes. F. BLAKOLMER, Das minoisch-mykenische ,Zahnornament" und die ionischen Apatourien. Eine farbengeschichtliche Vermutung, in: Festschrift für Friedrich Brein, Internet-Zeitschrift Forum Archaeologiae - Zeitschrift für klassische Archäologie (http://farch.net) 14/III/2000.

75 G. Rodenwald, Die Fresken des Palastes, Tiryns II, Mainz 1912, 118f. (Frgt. 152; als Sänftenträger gedeutet), Taf. XI:6. So auch Müller, Op. cit. (Anm. 21), 272 Anm. 4; Lurz, Op. cit. (Anm. 51), 43. Vgl. dazu auch die Sichtweise von A. Evans, The Minoan and Mycenaean elements in Hellenic life, JHS 32 (1912), 283, als „a man of northern race?". Da wir hier, wie RodEnwaldT, Op. cit., völlig korrekt erkannte, das Werk eines stilistisch eigenwillig schaffenden Malers vor uns haben, wird

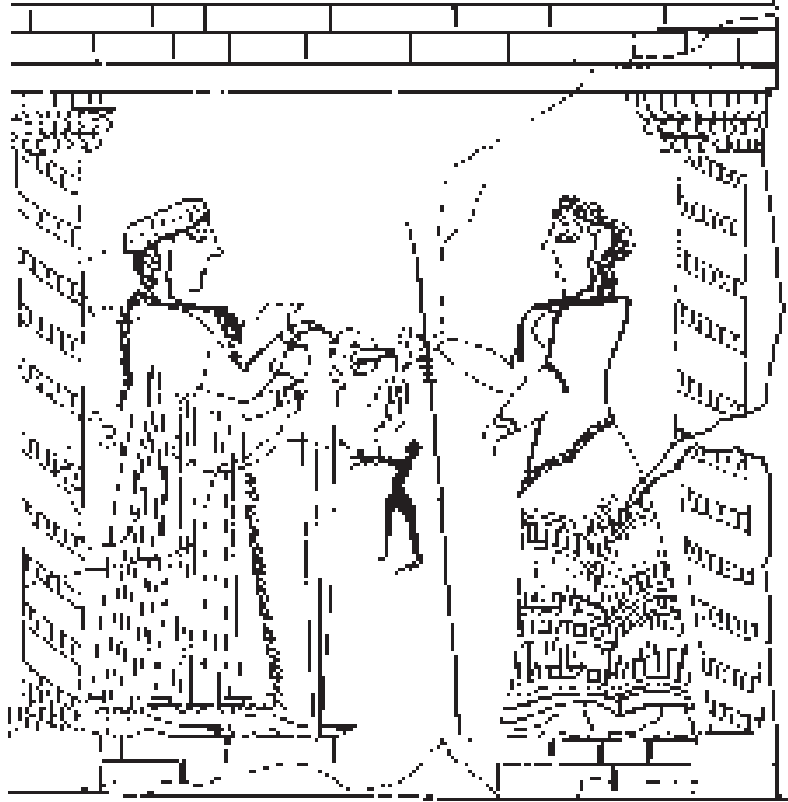

Abb. 18 Wandbild aus dem ,Cult Center“ von Mykene (Ausschnitt). Rekonstruktion von N. Marinatos (nach N. Marinatos in: E. B. French und K. A. Wardle [Hrsg.], Problems in Greek Prehistory. Papers Presented at the Centenary Conference of the British School of Archaeology at Athens, Bristol 1988, 251, Abb. 3; Zeichnung: L. Papageorgiou)

ren vergleichbaren Kriegerreihen, wie im theräischen Akrotiri, ${ }^{77}$ in Tiryns, ${ }^{78}$ Mykene ${ }^{79}$ und Orchomenos ${ }^{80}$ im allgemeinen keine Notwendigkeit für eine solche inkarnatsfarbliche Unterscheidung gesehen wurde.

man wohl auch an formale Aspekte dieser Art einen toleranteren Maßstab anlegen müssen.

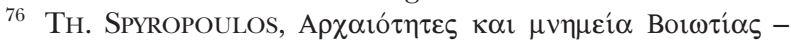

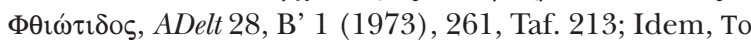

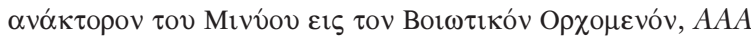
7, H. 3 (1974), 321, Farbtaf. IIb.

77 Morgan, Op. cit. (Anm. 16), 150-154, Abb. 144-145; CH. Doumas, The Wall-paintings of Thera, Athen 1992,

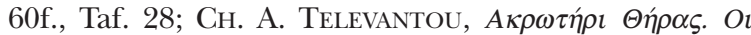

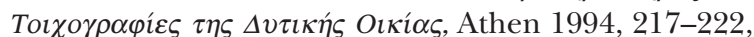
Taf. 34, 36-38; Beil. 2.

78 Rodenwaldt, Op. cit. (Anm. 75), 5-8, Taf. I:6. Siehe die Umzeichnung bei HöcKManN, Op. cit. (Anm. 59, 1980), 289, Abb. 74 b.

79 Siehe G. Rodenwaldt, Der Fries des Megarons von Mykenai, Halle 1921, 38-40, und vor allem das Fragment in: Idem, Fragmente mykenischer Wandgemälde, AM 36 (1911), 237f., Taf. XII.2, das die einander überschneidenden Beine von (mindestens) zwei laufenden Kriegern zeigt und dem Fresko des, Captain of the Blacks ikonographisch wohl am nächsten kommt.

80 Spyropoulos, Op. cit. (Anm. 76, 1973), 261, Taf. 213; Hiller, Op. cit. (Anm. 52), 322, 325, Taf. LXXI:11a; Idem, Op. cit. (Anm. 55), 33, Taf. 4.2. 
Andere mögliche Beispiele alternierenden Körperkolorits in der altägäischen Bildkunst sind in ihrer Aussage weniger eindeutig. Wie immer wir zum Beispiel die Farbgebung der roten und der schwarzen, geradezu als füllende ,Beizeichen“ in die Bildkomposition eingefügten kleinformatigen, nackten Männerfiguren zwischen den beiden weiblichen Gestalten im Wandbild aus dem ,Cult Center von Mykene (Abb. 18) zu verstehen haben, ${ }^{81}$ eine symbolistische Deutung dürfte ihnen wohl eher gerecht werden ${ }^{82}$ als eine ethnische. ${ }^{83} \mathrm{Zu}$ denken wäre etwa an eine Ableitung vom ägyptischen Verständnis gefesselter, nackter Feinde in Rot und in Schwarz in apotropäischem Sinne als ,blutig' (Rot) bzw. ,nicht-seiend“ (Schwarz) $;^{84}$ obwohl der kriegerische Aspekt in diesem Wandbild eindeutig gegeben ist, muß eine solche Deutung als symbolhaft vernichtete Kampfgegner in der Altägäis doch unbewiesen bleiben. Viel zu wenig wissen wir über den eventuellen Einsatz eines alternierenden Kolorits bei den großformatigen Stierspringer(innen) und möglicherweise weiteren Figuren in Stuckreliefs aus der ,Ost-Halle ' in Knossos, die sich mit rotem, weißem, aber auch orangem Inkarnat präsentieren. ${ }^{85}$ Erwähnenswert erscheint jedoch auch die gelbe

${ }^{81}$ Siehe bes. N. Marinatos, The fresco from room 31 at Mycenae: Problems of method and interpretation, in: E. B. French, K. A. Wardle (Hrsg.), Problems in Greek Prehistory. Papers Presented at the Centenary Conference of the British School of Archaeology at Athens, Bristol 1988, bes. 247f., Abb. 1, welche die Raison d'être dieser ungewöhnlichen Figuren im religiösen Charakter dieser Darstellung begründet sah

${ }^{82}$ Vgl. CuIne, Op. cit. (Anm. 4, 1994), 39: "perhaps a schematic representation of the Red Land and the Black Land in Egypt“. Contra: J. M. WeInSTEIn, BASOR 297 (1995), 91. Siehe weiters Marinatos, Op. cit. (Anm. 81).

${ }^{83}$ Siehe die Deutung der schwarzen Figur als Afrikaner bei ReHAK, Op. cit. (Anm. 73), 48f.; HaIder, Op. cit. (Anm. 2, 1996), bes. 138f. mit Abb. 3-5.

${ }^{84} \mathrm{Zu}$ dieser Farbensymbolik bei knienden Gefesselten und teils bereits Enthaupteten in den jüngeren Gräbern Ramses' VI. und Ramses' IX., jedoch auch bereits in älteren Unterweltsbüchern siehe etwa E. HoRnUnG, Tal der Könige. Die Ruhestätte der Pharaonen, Zürich-München 1982, 155 mit Abb. 65 und 135-136.

85 PoM III, 510-515, Abb. 355-359; Hood, Op. cit. (Anm. 8), 73-75, Abb. 56A-C; Kaiser, Op. cit. (Anm. 13), 279-282; IMMERWAHR, Op. cit. (Anm. 47), 52f., 85, 161f., 171 (Kn Nr. 8 e); R. HäGG, The ,East Hall‘. A forgotten

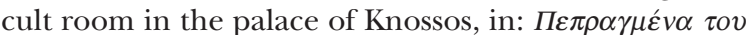

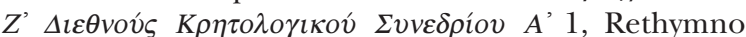
1995, 363-367; F. Blakolmer, Das minoisch-mykeni-
Kolorierung von Stierspringern auf Freskofragmenten unzweifelhaft minoischer Urheberschaft aus dem ägyptischen Tell el-Dabca ${ }^{86}$ für die ein jüngeres Alter, ${ }^{87}$ aber auch eine asiatische Herkunft ${ }^{88}$ vermutet wurde - Figuren mit minoischer Frisur bei der wohl ,minoischesten“ Tätigkeit, welche uns die kretische Bildkunst überliefert hat, und in einem Fall mit einem Polstersiegel am Handgelenk, wie uns dies in der minoisch-mykenischen Ikonographie für Ägäer gut bezeugt ist. ${ }^{89}$

Sollten wir aber nun in Analogie zu den genannten ägäischen und außer-ägäischen Beispielen die rot- und schwarzhäutigen Figuren im Fresko des ,Captain of the Blacks' mit ihren einander überschneidenden Beinen nicht auch unter dem zuvor erörterten Gesichtspunkt erklären? Zumindest plausibler wäre es, das schwarze Inkarnat der Figuren in diesem Beispiel losgelöst von der inhaltlichen Interpretationsebene und lediglich als farbstilistischen Kunstgriff der künstlerischen Spätzeit zu verstehen. Der Rekonstruktionsvorschlag in Abb. 22 soll zum Ausdruck bringen, daß dieses Wandbild eine mehrfigurige Reihe von Kriegern gezeigt haben könnte, die eine solche farbliche Konvention notwendig gemacht hätte. ${ }^{90}$ sche Stuckrelief. Zur Definition einer palatialen Kunstgattung der ägäischen Bronzezeit, in: F. Blakolmer, H. D. Szemethy (Hrsg.), Akten des 8. Österreichischen Archäologentages vom 23. bis 25. April 1999 am Institut für Klassische Archäologie der Universität Wien, Wiener Forschungen zur Archäologie 4, Wien 2001, 27-29; Idem, The Minoan Stucco Relief: A Palatial Art Form in Context, in:

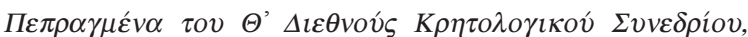

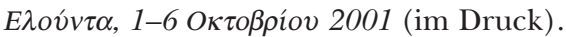

86 Bietak, Op. cit. (Anm. 3), 46-48 Taf. 15B; M Bietak, N. Marinatos, C. Palyvou, The maze tableau from Tell el Dabca, in: S. Sherratt (Hrsg.), Proceedings of the First International Symposium, The Wall Paintings of Thera; 30 August-4 September 1997, I, Athen 2000, 77-88, Abb. 1-5.

87 Bietak, Marinatos, Op. cit. (Anm. 3), 51 und 54.

88 J. G. Younger, Bronze Age representations of Aegean bull-games, III, in: R. LAFFInEUR, W.-D. NiemeIER (Hrsg.), POLITEIA. Society and State in the Aegean Bronze Age. Preceedings of the $5^{\text {th }}$ International Aegean Conference, University of Heidelberg, 10-13 April 1994, Aegaeum 12, II, (1995), 533.

89 Siehe bes. die Auflistung der Bildzeugnisse bei YounGER, Op. cit. (Anm. 88), 517f., Anm. 38; Idem, Nonsphragistic uses of Minoan-Mycenaean sealstones and rings, Kadmos 16 (1977), 147-149.

90 Zur Rekonstruktion siehe weiters Blakolmer Op. cit. (im Druck). 

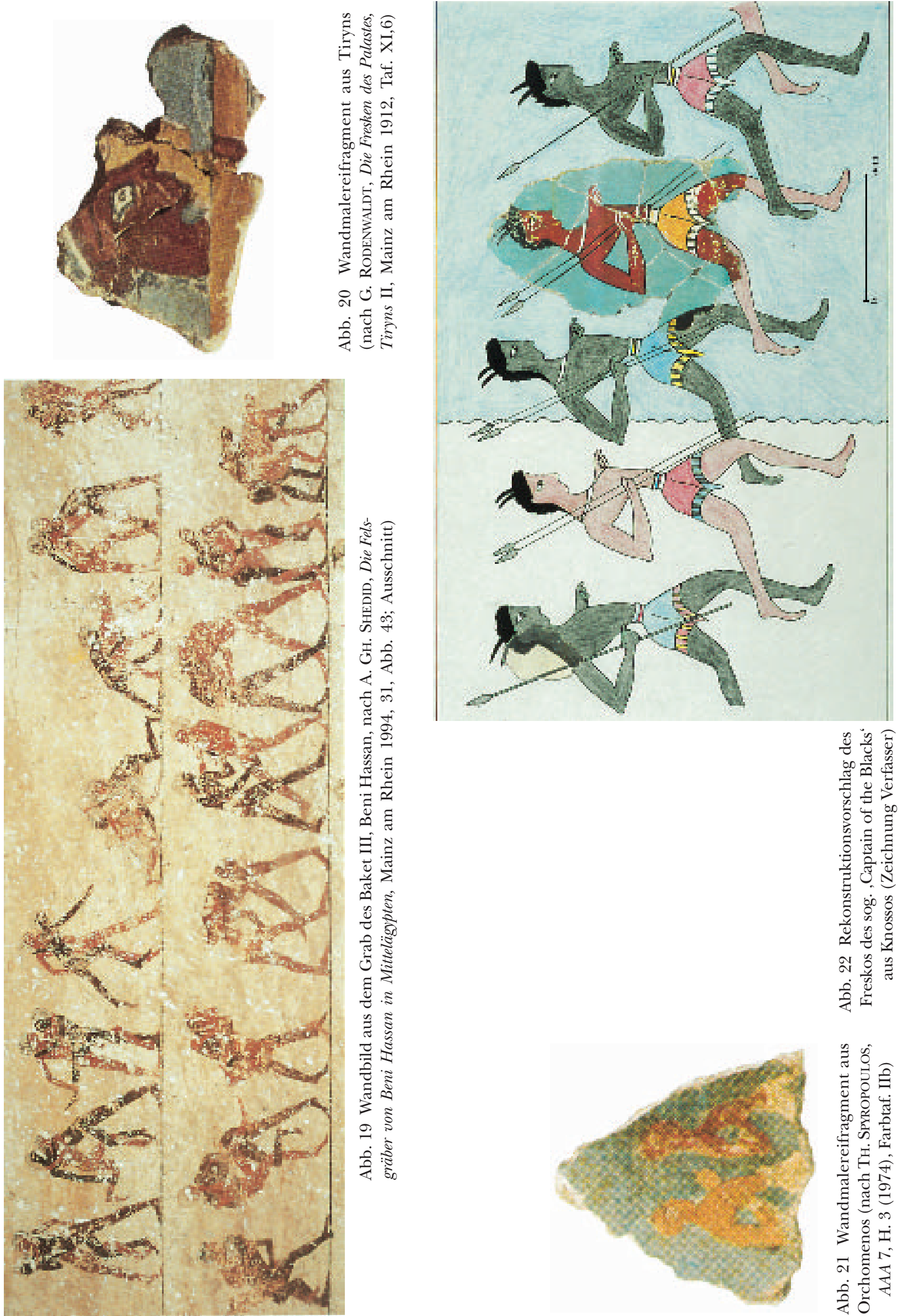


\section{Ergebnisse und Ausblick}

Halten wir folglich fest: Ein ikonographisches ,Vokabular' fremder ethnischer Charakteristika in wertender oder auch objektivierender Form läßt sich nach bisherigem Verständnis in der minoischen Bildkunst nicht mit Gewißheit feststellen. Die äußere Komponente einer ethnischen Differenzierung nach Tracht, Frisur und Hautfarbe begegnet immerhin vereinzelt auf dem mykenischen Festland. ${ }^{91}$ Eine ethnographische Unterscheidungsebene des physiognomischen Anders-Seins, etwa durch die Schilderung eines markanten Gesichtsprofils, eine vom Gewohnten abweichende Körperhöhe ${ }^{92}$ und andere optisch signifikante Merkmale, ist bislang jedoch in der Ägäis für die gesamte Bronzezeit nicht schlüssig nachgewiesen und sollte nicht a priori vorausgesetzt werden. Es hat durchaus den Anschein, als sei der Schritt zu einer konkret differenzierenden Physiognomie von Fremden in der Bildkunst Griechenlands erst in der archaischen Periode erfolgt und zwar im Falle

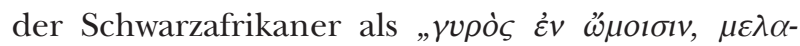

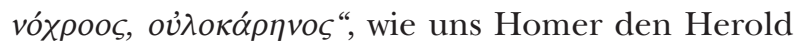
des Odysseus, Eurybates, schildert: ${ }^{93}$ "rund an den Schultern, dunkelhäutig und wollig das Haar".

Als multikulturelle Gesellschaften - durchaus im modernen Sinn - wird man sich zumindest die Zentren und Hafenstädte der bronzezeitlichen Agäis zweifellos vorstellen dürfen, auch wenn die

91 So etwa das genannte Wandbild aus dem Palast von Pylos (oben mit Anm. 47). Zur Zeichnung möglicherweise eines hethitischen Hörnerpolos auf einer mykenischen Scherbe aus dem kleinasiatischen Milet siehe H. G. Güterbock, Troy in Hittite texts? Wilusa, Ahhiyawa, and Hittite history, in: M. MeLlink (Hrsg.), Troy and the Trojan War. A Symposium Held at Bryn Mawr College, October 1984, Bryn Mawr 1986, 33-44, Abb. 4-5.

92 Dazu nun S. Hiller, Kleine Leute - Große Tiere. Themen der ägäischen Bildkunst in der späten Bronze- und der frühen Eisenzeit, in: F. Blakolmer, H. D. Szemethy (Hrsg.), Akten des 8. Österreichischen Archäologentages vom 23. bis 25. April 1999 am Institut für Klassische Archäologie der Universität Wien, Wiener Forschungen zur Archäologie 4, Wien 2001, 45-52. Vgl. auch P. J. P. McGEORGE, Mvөıкоí

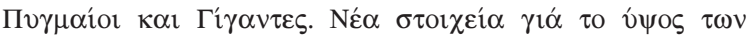

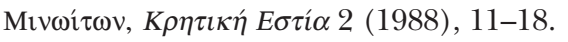

93 Hom. Od. 19, 246. Daß es sich hierbei nicht zwingend um einen Schwarzafrikaner handeln müsse, meinten D. Metzler, H. Hoffmann, Zur Theorie und Methode der Erforschung von Rassismus in der Antike, Kritische Berichte 5, H. 1 (1977), 14. Siehe allg. C. Dougherty, The Raft of Odysseus. The Ethnographic Imagination of Homer's Odysse, New York 2001.

94 Dazu etwa Driessen, MacDonald, Op. cit. (Anm. 56, physische Präsenz von Fremden bislang nur ansatzweise, insbesondere durch die spätmykenischen Linear B-Texte, tatsächlich greifbar ist. ${ }^{94}$ Über ethnozentrisch motivierte Wahrnehmungen fremdländischer Herkunft sagen diese Texte bislang leider nichts Näheres aus. ${ }^{95}$ Auch verbündete Partner und / oder unterjochte indigene Populationen der Kykladen, Kytheras, der Dodekanes oder in kleinasiatischen Küstenregionen, aber auch auf Kreta bzw. dem griechischen Festland selbst besaßen sicherlich eigene Kennzeichen wie Gewandung, Haar- und Barttracht sowie ökonomische Markenzeichen des Handels, so daß eine optische Differenzierbarkeit in der Realität wohl gegeben war. Folglich darf das Vorhandensein von tatsächlichen ,Fremdenbildern“ in der minoischen Welt nicht von vornherein ausgeschlossen werden. Die Erkennungskriterien, die wir im gegenwärtigen Denkmälerbestand nicht festmachen konnten, würden uns jedoch im zukünftigen Fundmaterial gegebenenfalls eine gänzlich neue Facette minoischer ,Bildsprache“ vor Augen führen.

Der ethnographisch motivierte Bildgedanke einer ,fremden“ oder zumindest einer ,fernen“ Lokalität, d.h. die ikonographische Unterscheidung zwischen dem ,Hier" und einem ,Dort', ist im Bild der Schiffsprozession des Südfrieses aus dem ,West-Haus ${ }^{96}$ im theräischen Akrotiri allerdings vorauszusetzen, muß doch zumindest eine der beiden dargestellten Siedlungen als das "Anderswo“

1984), 49-74; Carlier, Op. cit. (Anm. 5), bes. 9-16; Idem, La femme dans la société mycénienne d'après les archives en linéaire B, in: E. LÉVY (Hrsg.), La femme dans les sociétés antiques. Actes des colloques de Strasbourg, Mai 1980 et mars 1981, Strasbourg 1983, 9-32; J. CHADwick, The women of Pylos, in: J.-P. Olivier, T. G. PALAIMA (Hrsg.), Texts, Tablets and Scribes. Studies in Mycenaean Epigraphy and Economy Offered to Emmett L. Bennett, Jr, Minos Suppl. 10, Salamanca 1988, 43-95; E. SCAFA, Le relazioni esterne dei regni micenei: i testi in Lineare B, in: V. La Rosa, D. Palermo, L. Vagnetti (Hrsg.), $\dot{\varepsilon} \pi \dot{\imath}$ $\pi o ́ v \tau o v ~ \pi \lambda \alpha \zeta o ́ \mu \varepsilon v o r$. Simposio italiano di Studi Egei (dedicato a Luigi Bernabò Brea e Giovanni Pugliese Carratelli), Roma, 18-20 febbraio 1998, Rom 1999, 269-283.

95 Dies ist umso bedauerlicher, als gerade diese Informationsquelle im Gegensatz zu Kunst und archäologischer Sachkultur noch am ehesten Klarheit erwarten ließe. Zur vorliegenden Problematik im klassischen Griechenland vgl. bes. J. M. HALL, Ethnic Identity in Greek Antiquity, Cambridge 1995, 182: „... it is the literary evidence which must constitute the first and final frame of analysis in the study of ancient ethnicity. "

96 Doumas, Op. cit. (Anm. 77), 68-85, Taf. 35-48; TelevanTOU, Op. cit. (Anm. 77), 187-308, Taf. 4. 
verstanden werden. ${ }^{97}$ Auf eine unterschiedliche Charakterisierung exotischer Menschen, Architekturen und wohl auch Landschaften wurde jedoch selbst hier verzichtet, wenn man voraussetzt, daß ein sich verzweigender Fluß ${ }^{98}$ und ein heteromorphes Siedlungsbild ${ }^{99}$ ebenso innerhalb der Ägäis begegnen konnten.

Das Desinteresse der minoischen Hochkultur an einer Zurschaustellung des polyethnischen Momentes muß weder zwingend mit einem besonders ausgeprägten Ethnozentrismus in Verbindung gebracht werden, noch mit seinem Gegenteil. ${ }^{100}$ Es hat viel eher den Anschein, als läge in der ägäischen Bronzezeit tendenziös eine andere Definition des ,Fremden“ vor. Mit seiner Aussage, „[...] the ethnic groups probably did not exist as they are understood in the modern world", dürfte John Bennet den Kern des Problems erfaßt haben. ${ }^{101}$ Welche Faktoren auch immer für das Verständnis einer übergeordneten Identität in den frühägäischen Gesellschaften ausschlaggebend waren - etwa genealogische Wurzeln, gemeinsame Sprache, kulturelle Traditionen wie religiöse Bräuche und mythologische Vorstellungen, gemeinsames Recht, ein gemeinsam geteilter Vergangenheitsbezug oder andere Parameter $^{102}$-, das Bedürfnis nach einer differenzierenden Abgrenzung gegenüber dem ,Fremden“ im ethnischen Sinne läßt sich in der Ikonographie der minoischen Welt bislang nicht nachweisen, während im mykenischen Griechenland zumindest
97 Siehe z.B. Morgan, Op. cit. (Anm. 16), bes. 92f. Überlegenswert ist eine solche Gegenüberstellung von mindestens zwei Lokalitäten auch in den Miniaturfresken aus Agia Irini auf Kea: K. ABRAmovitz, Frescoes from Ayia Irini, Keos, II-IV, Hesperia 49 (1980), 57-71; L. MorgAN, Island iconography: Thera, Kea, Milos, in: D. A. HARDY, C. G. Doumas, J. A. Sakellarakis, P. M. Warren (Hrsg.), Thera and the Aegean World III. Proceedings of the Third International Congress, I, London 1990, 252-266; Eadem, The wall-paintings of Ayia Irini, Kea, BICS 40 (1995), 243f.; Eadem, The wall paintings of the North-East Bastion at Ayia Irini, Kea, in: L. G. Mendoni, A. I. MaZArakis Ainian (Hrsg.), Kea - Kythnos: History and Archaeology. Proceedings of an International Symposium, Kea - Kythnos, 22-25 June 1994, Meletimata 27, Paris 1998, 201-210.

98 Siehe allg. O. RACKHAM, J. MoODY, The Making of the Cretan Landscape, Manchester/New York 1996. Zum Gedanken, daß Tiryns in der Spätbronzezeit im Norden und im Süden von einem Flußlauf umgeben wurde und seine Topographie somit jener um ,Stadt II' des theräischen Miniaturfreskos mit ihrem ,Delta sehr ähnlich gekommen sein dürfte, siehe J. KNAUss, Die Flußumleitung von Tiryns, $A M 110$ (1995), bes. 80f. mit Abb. 1 und 14. Vgl. auch E. ZANGGER, Landscape changes around Tiryns during the Bronze Age, AJA 98 (1994), 189-212, bes. 209, Abb. 13. Zur Geologie von Tiryns siehe weiters Idem, The Geoarchaeology of the Argolid, Berlin 1993.

99 Zum Aussehen von architektonischen Ensembles in der frühen Ägäis siehe TH. NöRLING, Altägäische Architekturbilder, Archaeologica Heidelbergensia 2, Mainz 1994; B. RuTkowski, Frühgriechische Kultdarstellungen, AM Beih. 8, Berlin 1981, 11-34; M. HuE, Les représentations architecturales dans la peinture murale égéenne de l'âge du Bronze. L'exemple d'Akrotiri (Thera), in: R. Étienne, M.-Th. Le Dinahet, M. Yon (Hrsg.), Architecture et poésie dans le monde grec. Festschrift G. Roux, Lyon 1989, 79-90; Ch. Boulotis, Villes et palais dans l'art égéen du II millénaire av. J.-C., in: P. DARCQUe, R. TreuIL (Hrsg.),
L'habitat égéen préhistorique. Actes de la Table Ronde internationale organisé par le CNRS, l'Université de Paris I et l'École française d'Athènes (Athènes, 23-25 juin 1987), ВCH Suppl. XIX, Athen 1990, 421-459; G. HIEsEL, Späthelladische Hausarchitektur, Mainz 1990, bes. 229-237; M. KüPPER, Mykenische Architektur. Material, Bearbeitungstechnik, Konstruktion und Erscheinungsbild, Internationale Archäologie 2, Espelkamp 1996, bes. 111-118.

100 Dazu sehr anregend: Metzler, Hoffmann, Op. cit. (Anm. 93) 5-20; I. WeIler, Zur Xenophobie und ähnlichen Einstellungen gegenüber dem Fremden bei den Völkern der Alten Welt, in: W. Höflechner, H. J. Metzler, O. Pickl (Hrsg.), Domus Austriae. Eine Festgabe Hermann Wiesflecker zum 70. Geburtstag, Graz 1983, 426-435; P. W. HAIDER, Fremdarbeiter im Alten Ägypten, in: I. WEILER (Hrsg.), Soziale Randgruppen und Außenseiter im Altertum. Referate vom Symposion "Soziale Randgruppen und antike Sozialpolitik “ in Graz (21. bis 23. September 1987), Graz 1988, 303-311; J. Assmann, Herrschaft und Heil. Politische Theologie in Ägypten, Israel und Europa, Darmstadt 2000, 217-242.

101 J. Bennet, The meaning of ,Mycenaeans': Speculations on ethnicity in the Aegean Late Bronze Age, BICS 43 (1999), 224.

102 Siehe allg. Hall, Op. cit. (Anm. 95), bes 19-26; M.-F. BASLEZ, L'étranger dans la Grèce antique, Paris 1984; E. LÉVY, Naissance du concept de barbare, Ktèma 9 (1984), 5-14; P. Cartledge, The Greeks. A Portrait of Self and Others, Oxford-New York 1993; CH. UlF (Hrsg.), Wege zur griechischen Identität, Berlin 1996; F. DAIM, Gedanken zum Ethnosbegriff, Mitteilungen der Anthropologischen Gesellschaft Wien 112 (1982), 58-71; S. HiLler, Die Ethnogenese der Griechen aus der Sicht der Vorund Frühgeschichte, in: Ethnogenese europäischer Völker, Stuttgart-New York 1986, 21-37; S. JonES, The Archaeology of Ethnicity, London-New York 1997; I. MaLkin, The Returns of Odysseus. Colonization and Ethnicity, Berkeley u.a. 1998; Idem (Hrsg.), Ancient Perceptions of Greek Ethnicity, Cambridge, Mass.-London 2001. 
ansatzweise die Vorstellung des, Fremdländers“ und insbesondere jene des ,kulturlosen Wilden“ erkennbar ist. ${ }^{103}$

Die altkretische Ikonographie jedenfalls war primär von religiös-zeremoniellen Ideen bestimmt und baute offensichtlich nicht auf Mechanismen, die z.B. eine Präsentation unterworfener oder Geschenke bringender ,Nachbarn “ - sei es aus Ägypten, von den Kykladen oder der kleinasiatischen Westküste nahelegt. Kein minoischer Machthaber protzte mit seinem ,internationalen' oder über-regionalen Einfluß gegenüber benachbarten Reichen und Fürstenhöfen oder ließ sich als weltoffener Staatsmann präsentieren. ${ }^{104} \mathrm{Im}$ Gegensatz zum ägyptischen Pharao verstanden sich die minoischen Herrscher(innen) wohl nicht als virtuelle Weltbeherrscher mit hegemonialen Ansprüchen.

Doch auch das Phänomen der physiognomischen Individualisierung in der ägäischen Bildkunst gilt bislang als ungelöst, ja als nur fallweise andiskutiert. ${ }^{105}$ Dies bedeutet, selbst der Bildgedanke einer

${ }^{103} \mathrm{Zu}$,vor-mykenischen Wilden' in der Vorstellung der ,Mykener" vgl. bes. Bennet, Op. cit. (Anm. 101), 224: „... groups within LBA states beneath the upper levels of the power hierarchy“; J. L. DAVIS, J. BENNET, Making Mycenaeans: Warfare, territorial expansion, and representations of the Other in the Pylian kingdom, in: R. LAFFINEUR (Hrsg.), POLEMOS. Le contexte guerrier en Égée à l'âge du Bronze, Actes de la 7e Rencontre égéenne internationale, Université de Liège, 14-17 avril 1998, Aegaeum 19, II (1999), bes. 107-110 und 114-117. Siehe weiters J. Bennet, Space through time: Diachronic perspectives on the spatial organization of the Pylian state, in: R. LAfFineur, W.-D. NiemeIer (Hrsg.), POLITEIA. Society and State in the Aegean Bronze Age. Preceedings of the $5^{\text {th }}$ International Aegean Conference, University of Heidelberg, 10-13 April 1994, Aegaeum 12, II (1995), 587-602. Vgl. auch die Deutung der Träger von langem, wirrem Haar als "lower class people, shepherds, farmers and the like" bei N. Marinatos, The Tell el-Dabca paintings: a study in pictorial tradition, $\ddot{A} \mathcal{E} L 8$ (1998), 89. Ähnlich auch N. K. Sandars, The Sea Peoples. Warriors of the Ancient Mediterranean 1250-1150 BC, London 1978, 68, 70 mit Abb. 37. Siehe allg. A. O. Lovejoy, G. BoAs, Primitivism and Related Ideas in Antiquity, Baltimore-London 1935.

${ }^{104}$ Zur mykenischen Herrscherrepräsentation vgl. C. W. SHELmerdine, Administration in the Mycenaean palaces: Where's the chief?, in: M. L. Galaty, W. A. PARKInson (Hrsg.), Rethinking Mycenaean Palaces. New Interpretations of an Old Idea. The Cotsen Institute of Archaeology, University of California, Los Angeles Monograph 41, Los Angeles 1999, 20: „... we never see the king functioning as a military leader, a lawgiver, or an international statesman."

105 Zum Problem des Porträts in der minoisch-mykenischen Bildkunst siehe BIESANTZ, Op. cit. (Anm. 14), differenzierenden Schilderung der individuellen Persönlichkeit drängt sich uns bei der Betrachtung der Denkmäler keineswegs auf, ja scheint im minoischen Kreta - trotz der ersten Blüte realistischen Ausdrucks in der Bildwelt - zumindest weitgehend zu fehlen. Die Frage, ob der Umstand, daß uns das individuelle Herrscherporträt in der gesamten Ägäis generell fehlt, ${ }^{106}$ Folge oder Ursache dieser ungewöhnlichen Entwicklung ist, muß ebenfalls offen bleiben. Daß in diesem Gefüge einer, widerspenstigen Kultur ${ }^{{ }^{107}}$ auch unsere Suche nach einem echten Historienbild bislang erfolglos verlief, soll hier nur am Rande erwähnt werden.

Dieser in Hinblick auf das Verständnis des Fremden in der Bild- und Geisteswelt des minoischen Kreta zugegebenermaßen zu einem Minimalismus tendierende Ansatz besitzt m.E. deutlich höhere Wahrscheinlichkeit als ein in bezug auf diesen Aspekt möglicherweise verfrüht euphorischer Umgang mit der ägäischen Ikonographie. Kreta war einfach anders. ${ }^{108}$

9-25; Blegen, Op. cit. (Anm. 14), 245-247; S. MarinaTos, Minoische Porträts, in: D. Ahrens (Hrsg.), Festschrift Max Wegner zum 60. Geburtstag, Münster 1962, 9-12; BoARdMan, Op. cit. (Anm. 35), 115-117, Abb. 1, 2; Taf. 2, 3, 4:2; Kopcke, Op. cit. (Anm. 43), 1-13; Betts, Op. cit. (Anm. 14), 2-8; Wingerath, Op. cit. (Anm. 14), 88-91; Foster, Op. cit. (Anm. 21), 127-140; PINI, Op. cit. (Anm. 13), 661-670.

${ }^{106}$ Zur Diskussion der Problematik des Herrscherbildnisses in der Frühägäis siehe bes. die kritische Erörterung von E. N. DAVIS, Art and politics in the Aegean: The missing ruler, in: P. ReHAK (Hrsg.), The Role of the Ruler in the Prehistoric Aegean. Proceedings of a Panel Discussion Presented at the Annual Meeting of the Archaeological Institute of America, New Orleans, Louisiana, 28 December 1992, Aegaeum 11, (1995), 11-20; Shelmerdine, Op. cit. (Anm. 104), 19-24. Positiver fällt die Bewertung aus bei Hood, Op. cit. (Anm. 8), 218 (zu ,Porträts' auf mittelminoischen Siegelbildern: „... different heads, which might represent the features of a ruler of Knossos and members of his family rather than gods"); В. Отто, Hoheitszeichen in der altkretischen Kunst, in: F. Blakolmer (Hrsg.), Österreichische Forschungen zur Ägäischen Bronzezeit 1998. Akten der Tagung am Institut für Klassische Archäologie der Universität Wien, 2.-3. Mai 1998, Wiener Forschungen zur Archäologie 3, Wien 2000, 83-88.

${ }^{107}$ Dieser klingende Ausdruck wurde ein wenig sinnentfremdet entlehnt aus K. H. Hörning, R. Winter (Hrsg.), Widerspenstige Kulturen. Cultural Studies als Herausforderung, Frankfurt 1999.

${ }^{108}$ In Anlehnung an G. CAdOGan, Why was Crete different?, in: G. CADOGAN (Hrsg.), The End of the Early Bronze Age in the Aegean, Leiden 1986, 153-171. 